Babiloni C, Del Percio C, Lizio R, Noce G, Lopez S, Soricelli A, Ferri R, Pascarelli

MT, Catania V, Nobili F, Arnaldi D, Fama F, Orzi F, Buttinelli C, Giubilei F,

Bonanni L, Franciotti R, Onofrj M, Stirpe P, Fuhr P, Gschwandtner U, Ransmayr G, Garn H, Fraioli L, Pievani M, D'Antonio F, De Lena C, Guntekin B, Hanoglu L, Basar E, Yener G, Emek-Savas DD, Triggiani Al, Taylor JP, De Pandis MF, Vacca L, Frisoni GB, Stocchi F.

Functional cortical source connectivity of resting state

electroencephalographic alpha rhythms shows similar abnormalities in patients with mild cognitive impairment due to Alzheimer's and Parkinson's diseases.

Clinical Neurophysiology 2018, 129(4), 766-782

Copyright:

(C) 2018. This manuscript version is made available under the CC-BY-NC-ND 4.0 license

DOI link to article

https://doi.org/10.1016/j.clinph.2018.01.009

Date deposited:

$07 / 03 / 2018$

Embargo release date:

31 January 2019

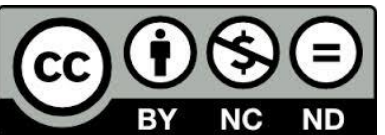

This work is licensed under a

Creative Commons Attribution-NonCommercial-NoDerivatives 4.0 International licence 


\title{
FUNCTIONAL CORTICAL SOURCE CONNECTIVITY OF RESTING STATE ELECTROENCEPHALOGRAPHIC ALPHA RHYTHMS SHOWS SIMILAR ABNORMALITIES IN PATIENTS WITH MILD COGNITIVE IMPAIRMENT DUE TO ALZHEIMER'S AND PARKINSON'S DISEASES
}

\author{
Claudio Babiloni ${ }^{1,2}$, Claudio Del Percio ${ }^{3}$, Roberta Lizio ${ }^{1,2}$, Giuseppe Noce ${ }^{3}$, Susanna Lopez ${ }^{1}$, Andrea Soricelli ${ }^{3,4}$, \\ Raffaele Ferri ${ }^{5}$, Maria Teresa Pascarelli ${ }^{5}$, Valentina Catania ${ }^{5}$, Flavio Nobili ${ }^{6}$, Dario Arnaldi ${ }^{6}$, Francesco Famà ${ }^{6}$, \\ Francesco Orzi ${ }^{7}$, Carla Buttinelli ${ }^{7}$, Franco Giubilei ${ }^{7}$, Laura Bonanni ${ }^{8}$, Raffaella Franciotti ${ }^{8}$, Marco Onofrj ${ }^{8}$, Paola \\ Stirpe ${ }^{2}$, Peter Fuhr ${ }^{9}$, Ute Gschwandtner ${ }^{9}$, Gerhard Ransmayr ${ }^{10}$, Heinrich Garn ${ }^{11}$, Lucia Fraioli ${ }^{12}$, Michela \\ Pievani $^{13}$, Fabrizia D'Antonio ${ }^{14}$, Carlo De Lena ${ }^{14}$, Bahar Güntekin ${ }^{15}$, Lutfu Hanoğlu ${ }^{16}$, Erol Başar ${ }^{17}$, Görsev Yener ${ }^{17}$, \\ Derya Durusu Emek-Savaş ${ }^{18}$, Antonio Ivano Triggiani ${ }^{19}$, John Paul Taylor ${ }^{20}$, Maria Francesca De Pandis ${ }^{12}$, Laura \\ Vacca $^{21}$, Giovanni B. Frisoni ${ }^{13,22}$, and Fabrizio Stocchi ${ }^{2}$ \\ ${ }^{1}$ Department of Physiology and Pharmacology "Vittorio Erspamer", University of Rome "La Sapienza", Rome, Italy; \\ ${ }^{2}$ Institute for Research and Medical Care, IRCCS San Raffaele Pisana, Rome, Italy; \\ ${ }^{3}$ Department of Integrated Imaging, IRCCS SDN, Naples, Italy; \\ ${ }^{4}$ Department of Motor Sciences and Healthiness, University of Naples Parthenope, Naples, Italy; \\ ${ }^{5}$ Department of Neurology, IRCCS Oasi Institute for Research on Mental Retardation and Brain Aging, Troina, Enna, Italy; \\ ${ }^{6}$ Clinical Neurology, dept of Neuroscience (DiNOGMI), University of Genoa and IRCCS AOU S Martino-IST, Genoa, Italy; \\ ${ }^{7}$ Department of Neuroscience, Mental Health and Sensory Organs, University of Rome "La Sapienza", Rome, Italy; \\ ${ }^{8}$ Department of Neuroscience Imaging and Clinical Sciences and CESI, University G d'Annunzio of Chieti-Pescara, Chieti, Italy; \\ ${ }_{9}$ Universitätsspital Basel, Abteilung Neurophysiologie, Petersgraben 4, 4031 Basel, Switzerland; \\ ${ }^{10}$ Department of Neurology 2, Med Campus III, Faculty of Medicine, Johannes Kepler University, Kepler University Hospital, Krankenhausstr. \\ 9, A-4020 Linz., Austria; \\ ${ }^{11}$ AlT Austrian Institute of Technology GmbH, Vienna, Austria; \\ ${ }^{12}$ Hospital San Raffaele of Cassino, Italy; \\ ${ }^{13}$ Laboratory of Alzheimer's Neuroimaging and Epidemiology, IRCCS Istituto Centro San Giovanni di Dio Fatebenefratelli, Brescia, Italy; \\ ${ }^{14}$ Department of Neurology and Psychiatry, Sapienza, University of Rome, Italy; \\ ${ }^{15}$ Istanbul Medipol University, Istanbul, Turkey; \\ ${ }^{16}$ Department of Neurology, University of Istanbul-Medipol, Istanbul, Turkey; \\ ${ }^{17}$ Department of Neurosciences and Department of Neurology, Dokuz Eylül University Medical School, Izmir, Turkey; \\ ${ }^{18}$ Department of Psychology and Department of Neurosciences, Dokuz Eylül University, Izmir, Turkey; \\ ${ }^{19}$ Department of Clinical and Experimental Medicine, University of Foggia, Foggia, Italy. \\ 20 Institute of Neuroscience, Newcastle University, Newcastle, UK. \\ ${ }^{21}$ Casa di Cura Privata del Policlinico (CCPP) Milano SpA, Milan, Italy. \\ ${ }^{22}$ Memory Clinic and LANVIE - Laboratory of Neuroimaging of Aging, University Hospitals and University of Geneva, Geneva, Switzerland;
}

Corresponding author: Prof. Claudio Babiloni, Ph.D.

Department of Physiology and Pharmacology "V. Erspamer"

University of Rome "La Sapienza"

P. le A. Moro 5, 00185, Rome, Italy

Phone: +390649910989

E-mail: claudio.babiloni@uniroma1.it

Running title: Functional brain connectivity in mild cognitive impairment.

Keywords: Functional brain connectivity; Resting state EEG rhythms; Mild cognitive impairment due to Alzheimer's disease (ADMCI); Mild cognitive impairment due to Parkinson's disease (PDMCI).

\begin{abstract}
Acknowledgements
The present study was developed based on the data of the informal European Consortium PDWAVES and European Consortium of Dementia with Lewy Body. The members and institutional affiliations of the Consortia are reported in the cover page of this manuscript. Dr. Erol Başar passed away due to health problems on October 28th (November 18th 1938 - October 28th 2017) in Istanbul, during the editorial processing of this manuscript. Until the end of his life, he had been working to the development of EEG science and its application in Clinical Neurophysiology. He leaves to all us an invaluable scientific legacy in the Science of Brain Rhythms and Human Cognition. He also leaves a permanent reminder of scientific passion, academic soul, and social responsibility to all fortunate people who met and knew him during his intense life.The research activities of the Unit of University of Rome "La Sapienza" were partially supported by the H2020 Marie S. Curie ITN-ETN project with the short title "BBDiag" (http://bbdiag-itn-etn.eu). We thank Mrs. Jessica Janson and Mrs. Marina Selivanova for their support to those activities in the framework of the BBDiag project.
\end{abstract}




\section{Highlights}

$>\quad$ Alpha source connectivity was similarly reduced in both mild cognitive impairment due to Alzheimer's (ADMCI) and Parkinson's (PDMCI) disease.

$>\quad$ Delta source connectivity was normal in those groups.

Alpha source connectivity might reflect (common) cholinergic impairment in ADMCI and PDMCI. 


\section{Abstract}

Objective: This study tested the hypothesis that markers of functional cortical source connectivity of resting state eyes-closed electroencephalographic (rsEEG) rhythms may be abnormal in subjects with mild cognitive impairment due to Alzheimer's (ADMCI) and Parkinson's (PDMCI) diseases compared to healthy elderly subjects (Nold).

Methods: rsEEG data had been collected in $A D M C l, P D M C l$, and Nold subjects ( $N=75$ for any group). eLORETA freeware estimated functional lagged linear connectivity (LLC) from rsEEG cortical sources. Area under receiver operating characteristic (AUROC) curve indexed the accuracy in the classification of Nold and $\mathrm{MCl}$ individuals.

Results: Posterior interhemispheric and widespread intrahemispheric alpha LLC solutions were abnormally lower in both $\mathrm{MCl}$ groups compared to the Nold group. At the individual level, AUROC curves of LLC solutions in posterior alpha sources exhibited moderate accuracies $(0.70-0.72)$ in the discrimination of Nold vs. ADMCI-PDMCI individuals. No differences in the LLC solutions were found between the two $\mathrm{MCl}$ groups.

Conclusions: These findings unveil similar abnormalities in functional cortical connectivity estimated in widespread alpha sources in $\mathrm{ADMCl}$ and PDMCI. This was true at both group and individual levels.

Significance: The similar abnormality of alpha source connectivity in $A D M C l$ and $P D M C l$ subjects might reflect common cholinergic impairment. 


\section{Introduction}

About $50-70 \%$ of 46 million of cases of dementia worldwide are due to Alzheimer's (ADD) and Parkinson's (PDD) neurodegenerative diseases across aging (Prince et al., 2015). ADD typically presents a major amnesic syndrome and minor linguistic, visuospatial, and visual disease variants (Dubois et al., 2014). PDD manifest attentional, verbal, and executive cognitive deficits in association with motor manifestations such as akinesia, tremor, postural instability, and rigidity (Aarsland et al., 2003; Buter et al., 2008; Dubois and Pillon, 1996; Emre et al., 2007; Huber et al., 1989; Hughes et al., 2000; Levy et al., 2000; Walker et al., 2015; Wolters, 2001). These cognitive deficits can be observed before the diagnosis of dementia (i.e. major cognitive disorders and disabilities) in the clinical condition called mild cognitive impairment $(\mathrm{MCl})$, which is considered as a pre-dementia stage of neurodegenerative disorders.

Previous studies have shown that resting state eyes-closed electroencephalographic (rsEEG) rhythms may probe the neurophysiological "reserve" in patients with ADMCl and PDMCl, defined as the residual ability of the brain to ensure (1) the synchronization of neural activity at different spatial scales and frequencies from small cellular populations to large regions and (2) the coordination of that synchronization across subcortical and cortical neural networks (Babiloni et al., 2016a; 2017). The latter might be especially relevant to understand the pathophysiological mechanisms underlying different neurodegenerative disorders, as human cognition is based on a coordinated neurotransmission within large-scale networks (D’Amelio and Rossini, 2012; Pievani et al., 2011).

As far as the "functional cortical connectivity" markers are concerned, it has been reported that compared with normal elderly (Nold) subjects, ADD patients point to lower spectral coherence between electrode pairs in posterior alpha $(8-12 \mathrm{~Hz})$ and beta $(13-20 \mathrm{~Hz})$ rhythms (Adler et al., 2003; Anghinah et al., 2000; Besthorn et al., 1994a; Dunkin et al., 1994; Fonseca et al., 2013, 2011, Jelic et al., 2000, 1996; Knott et al., 2000; Leuchter et al., 1994, 1987, 1992; Locatelli et al., 1998; Pogarell et al., 2005; Sloan et al., 1994). However, these effects are topographically variable being observed in temporo-parieto-occipital electrode pairs in some studies (Adler et al., 2003; Locatelli et al., 1998; Jelic et al., 1996, 2000) yet in other studies in frontocentral electrode pairs (Besthorn et al., 1994; Fonseca et al., 2013; Leucther et al., 1994). Furthermore, some studies report a decrease of rsEEG coherence at low 
frequencies, especially at central electrodes in the theta band (Adler et al., 2003; Knott et al., 2000). Other studies report an increase in widespread delta coherences (Babiloni et al., 2010) or a quite complex topographical pattern of coherence increases and decreases (Sankari et al., 2011). Finally, studies using alternative techniques measuring rsEEG functional coupling show a decrement of synchronization likelihood in frontoparietal alpha rhythms in ADD patients and those with the pre-dementia stage of amnesic mild cognitive impairment $(\mathrm{aMCl})$ compared with Nold subjects (Babiloni et al., 2004, 2006a). Furthermore, directed transfer function (DTF) exhibited a lower flow of information between EEG signals in alpha and beta from parietal to frontal electrodes in $\mathrm{ADD}$ and $\mathrm{aMCl}$ patients compared with Nold subjects (Babiloni et al., 2009; Dauwels et al., 2010, 2009). Moreover, Canuet et al. (2012) reported a decrease in alpha 2 lagged phase synchronization between temporal and parietal electrodes in ADD patients compared with Nold subjects, and an increase in low frequency rsEEG rhythms, specifically in the theta band, between and within hemispheres. Nevertheless, in aMCl compared to Nold subjects, the opposite result was found, i.e. decreased phase lag index in the delta and theta rhythms within the frontal and between the frontal and temporal/parietal areas, with more pronounced effects 1 year later (Tóth et al., 2014).

In PD individuals, abnormal "functional cortical connectivity" was consistently revealed by rsEEG coherence between electrode pairs. Compared to Nold subjects, PD patients showed lower local intrahemispheric parietal alpha coherence (Moazami-Goudarzi et al., 2008). Furthermore, intrahemispheric cortico-cortical frontoparietal alpha and beta coherences were positively correlated with the severity of PD motor symptoms in the patients (Silberstein et al., 2005). Both L-dopa regimen and electrical stimulation of subthalamic nucleus reduced those coherences in association with an improvement of motor symptoms (Silberstein et al., 2005). Other evidence revealed a positive correlation between PD duration and beta coherence between rsEEG rhythms recorded in supplementary motor and primary motor areas (Pollok et al., 2013).

Concerning the relationship between "functional cortical connectivity" and cognition, PD patients with cognitive deficits demonstrate a positive correlation between decreased intrahemispheric frontoparietal alpha coherence and executive dysfunctions(Teramoto et al., 2016). Furthermore, PDD patients exhibit greater interhemispheric frontal alpha-beta and 
intrahemispheric fronto-occipital beta coherences than ADD patients do (Fonseca et al., 2013).

Recently, we have introduced a procedure combining (1) a source estimation technique called exact low-resolution brain electromagnetic tomography (Pascual-Marqui, 2007a) and (2) an analysis of rsEEG rhythms based on the "individual alpha frequency peak" (IAF; Klimesch, 1999; Klimesch et al., 1998, 1996). With this approach, we have tested the hypothesis that eLORETA source activity of scalp rsEEG rhythms might show differences in markers of cortical neural "synchronization/desynchronization" obtained in ADMCI and PDMCl patients compared with Nold subjects (Babiloni et al., 2017). As main findings, abnormalities in IAF showed abnormal lower frequencies in the PDMCI than the ADMCI group (Babiloni et al., 2017). Furthermore, compared with Nold subjects, the ADMCI and PDMCI patients showed robust abnormalities in rSEEG cortical source activity with some differences even between the diseased groups. Compared with Nold subjects, posterior alpha source activities were more abnormal in the $\mathrm{ADMCl}$ than the $\mathrm{PDMCl}$ group, while the parietal delta source activities were more abnormal in the PDMCI than the $A D M C l$ group (Babiloni et al., 2017). Finally, the parietal delta and alpha sources correlated with the mini-mental evaluation (MMSE) score of global cognition and correctly classified (area under the receiver operating characteristic, AUROC, curve $=0.77-0.79$ ) the Nold and diseased individuals (Babiloni et al., 2017).

As mentioned above, the "synchronization/desynchronization" of large cortical neural populations and the coordination of that synchronization across brain networks as a sign of "connectivity" may reveal complementary (no redundant) aspects of the neurophysiological "reserve" probed by rsEEG rhythms (Babiloni et al., 2016a). For this reason, the present retrospective study re-analyzed the original rsEEG database used in the mentioned reference investigation (Babiloni et al., 2017) to extract and compare markers of "functional cortical connectivity" in delta and alpha sources in Nold, $\mathrm{ADMCl}$, and PDMCl subjects. Keeping in mind the previous reference results based on "synchronization/desynchronization" markers (Babiloni et al., 2017), the present study tested the primary hypothesis that compared to Nold subjects, $\mathrm{ADMCl}$ and PDMCl patients may show abnormal rsEEG cortical source connectivity at the group and the individual level. In a more exploratory way, we also tested the potential differences in the rSEEG cortical source connectivity between $\mathrm{ADMCl}$ and PDMCl subjects. To 
facilitate the comparison with the results of the previous investigation (Babiloni et al., 2017), the present study adopted a similar data analysis design. ANOVAs tested differences in LLC solutions between pairs of groups (i.e., Nold, ADMCl, and PDMCI). Furthermore, correlation and classification (i.e., AUROC curve analysis) procedures tested if the LLC solutions showing differences between the groups conveyed information contents at the individual level. The main expectation was that compared with rSEEG markers of "synchronization/desynchronization", those of "functional cortical connectivity" might enrich the clinical neurophysiological model of the prodromal stage of $A D$ and PD compared with controls with normal cognition.

\section{Materials and Methods}

Details on the subjects, diagnostic criteria, rsEEG recording, and preliminary data analysis were reported in detail in the reference paper (Babiloni et al., 2017). However, we will provide a short description of those methodological procedures for readers' convenience in the following sections.

\section{Subjects and diagnostic criteria}

As we mentioned in the Introduction section, the present study re-analyzed the rsEEG data of an international archive, formed by clinical, neuropsychological, and electrophysiological data in $75 \mathrm{Nold}, 75 \mathrm{ADMCl}$, and $75 \mathrm{PDMCl}$, subjects (Babiloni et al., 2017). The three groups of subjects (i.e. PDMCl, ADMCl, and Nold) were carefully matched for age, gender, and education. The two groups of $\mathrm{MCl}$ patients were also carefully matched for the MMSE score (Folstein et al., 1975). Table 1 reports details of the above variables in the three groups. All subjects gave their written informed consensus to the use of the clinical, neuropsychological, and any other data collected from their persons for academic scientific studies with the condition that their identity was secured.

\section{Insert here Table 1}

The inclusion criteria for the enrollment of the ADMCI patients were (1) age between 55 and 90 years; (2) complaints of memory deficits by the patient (and confirmed by a relative) or a relative; (3) MMSE score $\geq 24$, overall Clinical Dementia Rating (CDR; Morris, 1993) score of 0.5 ; (4) score on the logical memory test (Wechsler, 1987) of 1.5 standard deviation (SD) 
lower than the age-adjusted mean; (5) 15-item Geriatric Depression Scale (GDS; Brown and Schinka, 2005) score $\leq 5$; and (6) modified Hachinski ischemia (Rosen et al., 1980) score $\leq 4$ and at least 5 years of education. The $\mathrm{MCl}$ status could be single or multi-domain.

The status of the ADMCI was based on the "positivity" to one or more of the following biomarkers: $A \beta 1-42 /$ phospho-tau in the cerebrospinal fluid (CSF), Fluorodeoxyglucose positron emission tomography (FDG-PET) mapping of hippocampus, parietal, temporal, and posterior cingulate regions, and structural magnetic resonance imaging (MRI) of hippocampus, parietal, temporal, and posterior cingulate regions (Albert et al., 2011). The "positivity" was based on the judgement of "abnormality" of the readout given by physicians in charge for the diagnosis of patients, according to the local diagnostic routine of the participating clinical Units. The judgement was done before the planning of the present retrospective study, so it can be considered as "blind".

Exclusion criteria for the ADMCI patients were other significant neurological, systemic or psychiatric illness, mixed neurodegenerative diseases, enrolment in a clinical trial with experimental drugs, the use of antidepressant drugs with anticholinergic side effects, high dose of neuroleptics or chronic sedatives or hypnotics, antiparkinsonian medication and the use of narcotic analgesics. Of note, the use of cholinesterase inhibitors and Memantine was allowed.

All $A D M C l$ subjects underwent a battery of neuropsychological tests (for details see (Babiloni et al., 2017).

The diagnosis of PD was based on a standard clinical assessment of tremor, rigidity, bradykinesia, and postural instability without major cognitive deficits for 12 months in accordance with the UK PD Brain Bank Criteria (Gelb et al., 1999). As measures of severity of the motor disability, the Hoehn and Yahr stage (Hoehn and Yahr, 1967), and the Unified Parkinson Disease Rating Scale-III (UPDRS-III; Fahn and Elton, 1987) for extrapyramidal symptoms, were used.

The status of the PDMCl was based on the Diagnostic Criteria for Mild Cognitive Impairment in Parkinson's Disease (Litvan et al., 2011). The inclusion criteria comprised: (1) a diagnosis of PD as specified above; (2) a gradual decline, in the context of an established PD, in the cognitive status reported by either the patient or informant, or observed by the clinicians; (3) cognitive deficits not sufficient to interfere significantly with functional 
independence in the activities of the daily life, although slight difficulties on complex functional tasks may be present. On the basis of clinical features and neuroradiological findings, the exclusion criteria for PDMCl included the following forms of parkinsonism: (1) Dementia with Lewy Body (Geser et al., 2005; McKeith et al., 2005, 1996), (2) drug-induced parkinsonism, (3) cerebrovascular parkinsonism, (4) atypical parkinsonism with absent or minimal responses to antiparkinsonian drugs, and (5) mixed neurodegenerative diseases.

All PDMCI subjects also underwent a battery of clinical scales and neuropsychological tests (for details see (Babiloni et al., 2017).

All Nold subjects underwent a cognitive screening (including MMSE and GDS) as well as physical and neurological examinations to exclude any dementia or major cognitive deficit or psychiatric disorder.

\section{rsEEG recordings and preliminary data analysis}

The rsEEG data were recorded while subjects kept their eyes closed in a relaxed state, not moving or talking. About five minutes of rsEEG data were recorded (128 Hz or higher sampling rate, with related antialiasing bandpass between $0.01 \mathrm{~Hz}$ and $100 \mathrm{~Hz}$ ) from 19 scalp electrodes positioned according to the 10-20 System (i.e. Fp1, Fp2, F7, F3, Fz, F4, F8, T3, C3, $\mathrm{Cz}, \mathrm{C} 4, \mathrm{~T} 4, \mathrm{~T} 5, \mathrm{P} 3, \mathrm{Pz}, \mathrm{P} 4, \mathrm{~T} 6, \mathrm{O} 1$, and $\mathrm{O} 2)$. A ground electrode was located in frontal region. Electrodes impedances were kept below $5 \mathrm{Kohm}$. Horizontal and vertical electro-oculographic activities (0.3-70 Hz bandpass) were also recorded to monitor blinking and eye movements. Linked earlobe reference electrode was preferred, but not mandatory to take into account the methodological facilities and standard internal protocols of the clinical recording units (137 subjects out of 225 subjects were recorded with linked earlobe reference, while the others with cephalic reference).

The rsEEG data were centrally analyzed in blind about the subjects' diagnosis at University of Rome "La Sapienza". Specifically, the were divided into segments of 2 seconds and analyzed off-line. The epochs affected by any physiological (ocular, muscular, head movements) or non-physiological (bad contact electrode-scalp) artifacts were preliminarily identified by an automatic computerized procedure (Moretti et al., 2003). Two independent experimenters manually checked and (dis)confirmed the artifact-free rsEEG epochs, before successive analyses. 
A standard digital FFT-based power spectrum analysis (Welch technique, Hanning windowing function, no phase shift) computed the power density of scalp rsEEG rhythms with $0.5 \mathrm{~Hz}$ of frequency resolution.

The frequency bands of interest were individually identified based on the following frequency landmarks: the transition frequency (TF) and the IAF. In the EEG power density spectrum, the TF marked the transition frequency between the theta and alpha bands, defined as the minimum of the rSEEG power density between 3 and $8 \mathrm{~Hz}$ (between the delta and the alpha power peak). Instead, the IAF was defined as the maximum power density peak between 6 and $14 \mathrm{~Hz}$. These frequency landmarks were originally introduced in the individual frequency analysis of EEG activity by Dr. Wolfgang Klimesch (Klimesch, 1996, 1999; Klimesch et al., 1998).

The TF and IAF were computed for each subject involved in the study. Based on the TF and IAF, we estimated the individual delta, theta, and alpha bands as follows: delta from TF $4 \mathrm{~Hz}$ to TF $-2 \mathrm{~Hz}$, theta from TF $-2 \mathrm{~Hz}$ to TF, low-frequency alpha (alpha 1 and alpha 2) from TF to IAF, and high-frequency alpha (or alpha 3) from IAF to IAF $+2 \mathrm{~Hz}$. In detail, the individual alpha 1 and alpha 2 bands were computed as follows: alpha 1 from TF to the frequency midpoint of the TF-IAF range and alpha 2 from that midpoint to IAF. The other bands were defined based on the standard fixed frequency ranges used in the reference study (Babiloni et al., 2017): beta 1 from 14 to $20 \mathrm{~Hz}$, beta 2 from 20 to $30 \mathrm{~Hz}$, and gamma from 30 to $40 \mathrm{~Hz}$. Of note, the choice of the division of alpha band into sub-bands was due to the fact that, in the eyes-closed rsEEG condition, dominant low-frequency alpha rhythms (alpha 1 and alpha 2) may denote the synchronization of diffuse neural networks regulating the fluctuation of the subject's global awake and conscious states, while high-frequency alpha rhythms (alpha 3) may denote the synchronization of more selective neural networks specialized in the processing of modal specific or semantic information (Klimesch, 1999; Pfurtscheller and Lopes da Silva, 1999). When the subject is engaged in sensorimotor or cognitive tasks, alpha and low-frequency beta (beta 1) rhythms reduce in power (i.e., desynchronization or blocking) and are replaced by fast EEG oscillations at high-frequency beta (beta 2) and gamma rhythms (Pfurtscheller and Lopes da Silva, 1999).

Previous evidence showed that alpha power frequency-by-frequency might show a certain variability within the alpha band due to several physiological signals and instrumental noise (Nikulin at el., 2011). For this reason, we estimated the alpha-band variability (alpha 
variability) based on the IAF and TF, and used it as a covariate in the main statistical analysis. Specifically, alpha variability was defined as the ratio between the alpha max and alpha extended. The alpha max was computed as the amplitude of cortical sources activity in the frequency range between IAF-1 and IAF+1 Hz, whereas the alpha extended was calculated as the amplitude of cortical source activity in the frequency ranges from TF to IAF-1 Hz and from IAF-1 to IAF+1 Hz. We used the freeware called exact LORETA (eLORETA) for the linear estimation of the cortical sources activity of rsEEG rhythms (for details see the reference study Babiloni et al., 2017).

Statistical analysis was performed to evaluate the differences in the alpha variability in the following comparisons: $\mathrm{MCl}$ groups vs. Nold group (i.e., $\mathrm{ADMCl}$ and $\mathrm{PDMCl} \neq \mathrm{Nold}$ ) and

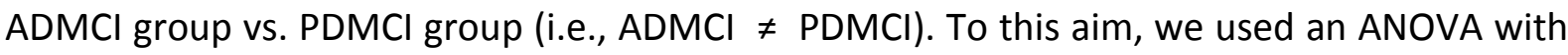
the alpha variability as a dependent variable $(p<0.05)$. The alpha variability values were preliminarily transformed using the log10 function to have a Gaussian distribution as revealed by Kolmogorov-Smirnov test (all log10 transformed alpha variability values presented a Gaussian distribution in the three groups, $p>0.05$ ). The ANOVA factors were Group (Nold, $\mathrm{ADMCl}$, and $\mathrm{PDMCl}$ ) and ROI (frontal, central, parietal, occipital, and temporal). Duncan test was used for post-hoc comparisons (Bonferroni corrected $p<0.05$ ). The results showed a significant interaction Group X ROI $(F=17.5, p=0.00001)$. Duncan planned post-hoc $(p<$ 0.0033 to obtain the Bonferroni correction at $p<0.05)$ testing revealed that the discriminant LLC pattern ADMCI and PDMCl < Nold was fitted by the central $(p<0.00001)$, parietal $(p<$ $0.000005)$, occipital ( $p<0.000005)$, and temporal $(p<0.00005)$ sources. The discriminant pattern PDMCI $<A D M C l$ was fitted by the same sources $(p<0.0002)$. The present results suggest that the alpha variability was different among Nold, $\mathrm{ADMCl}$, and PDMCI. Therefore, we used the alpha variability as a covariate in the further statistical analysis on LLC solutions.

\section{Estimation of functional connectivity of rsEEG cortical sources}

The eLORETA freeware was used to estimate the "functional cortical connectivity" from rsEEG rhythms (Pascual-Marqui, 2007b). Specifically, we used the toolbox called lagged linear connectivity (LLC; Pascual-Marqui et al., 2011). LLC provides linear measurements (hereinafter LLC solutions) of the statistical interdependence of pairs of eLORETA cortical source activations estimated from scalp rsEEG rhythms at a given frequency. The procedure 
provides LLC solutions between all combinations of voxels in the cortical source space of eLORETA (Pascual-Marqui et al., 2011). In its practical use, researchers can average those LLC solutions across eLORETA voxels for pairs of regions of interest (ROIs).

Noteworthy, LLC solutions are estimated by removing the zero-lag instantaneous phase interactions between rSEEG cortical sources estimated by eLORETA freeware. The rationale is that these zero-lag phase interactions could be affected by instantaneous physical propagation of neural ionic currents from a given source to all the others merely due to head volume conductor effects (Pascual-Marqui, 2007b). Furthermore, the LLC solutions took into account measures of interdependence among multivariate rsEEG time series, thus partially mitigating the so-called "common drive/source" effect of a "third" source on the LLC solutions estimated between two sources of interest (Pascual-Marqui, 2007c).

For each subject and frequency band of interest (i.e. delta, theta, alpha 1, alpha 2, alpha 3, beta 1, beta 2, and gamma), LLC solutions were computed for 5 ROls, namely frontal, central, parietal, occipital, and temporal lobes in the eLORETA cortical source space (PascualMarqui, 2007a).

For the interhemispheric analysis, the LLC solutions were calculated between all voxels of the mentioned ROls of each hemisphere with the homologous ones of the other hemisphere. The LLC solutions for all voxels of a given pair of ROIs were averaged. For each frequency band of interest, the following 5 interhemispheric LLC solutions were computed: frontal (i.e. frontal left - frontal right LLC), central (i.e. central left - frontal central LLC), parietal (i.e. parietal left - parietal right LLC), occipital (i.e. occipital left - occipital LLC), and temporal (i.e. temporal left - temporal right LLC).

For the intrahemispheric analysis, the LLC solutions were computed for all voxels of a particular ROI with all voxels of another ROI of the same hemisphere. The LLC solutions for all voxels of a given pair of ROIs were averaged. This operation was repeated for the left and the right hemisphere, separately. In particular, for each frequency band of interest and the left hemisphere, the following 5 left intrahemispheric LLC solutions were computed: (1) frontal (i.e., mean among left frontal - central, left frontal - parietal, left frontal - temporal, and left frontal - occipital LLC), (2) central (i.e., mean among left central - frontal, left central - parietal, left central - temporal, and left central - occipital LLC), (3) parietal (i.e., mean among left parietal - frontal, left parietal - central, left parietal - temporal, and left parietal - occipital LLC), 
(4) occipital (i.e., mean among left occipital - frontal, left occipital - central, left occipital parietal, and left occipital - temporal LLC), and (5) temporal (i.e., mean among left temporal frontal, left temporal - central, left temporal - parietal, and left temporal - occipital LLC). The same procedure was repeated for the right hemisphere.

Of note, the five ROls (i.e., frontal, central, parietal, occipital, and temporal), even if bigger than that obtainable by anatomical oriented template like Automated Anatomical Labeling (Marino et al., 2016), may be acceptable when applied to the cortical source estimation of eyes-closed resting state EEG rhythms for at least three reasons: (1) the eyesclosed rsEEG rhythms are widely represented across human cerebral cortex, in contrast to the circumscribed functional topography of event-related EEG changes (Babiloni et al., 2016a); (2) the spatial resolution of rsEEG recording with 19 scalp electrodes positioned according to the 10-20 System is low; and (3) the spatial resolution of the eLORETA solutions is low for its peculiar maximally-smoothing regularization procedure (Pascual-Marqui, 2007b).

\section{Statistical analysis of the LLC of rsEEG cortical sources}

A statistical session was performed by the commercial tool STATISTICA 10 (StatSoft Inc., www.statsoft.com) to test the hypothesis that the "functional cortical connectivity" as A statistical session was performed by the commercial tool STATISTICA 10 (StatSoft Inc., www.statsoft.com) to test the hypothesis that the "functional cortical connectivity" of rsEEG rhythms as revealed by the eLORETA LLC between rSEEG source pairs (hereinafter LLC solutions) may be abnormal in the $\mathrm{ADMCl}$ and $\mathrm{PDMCl}$ groups compared to the Nold group. Furthermore, an exploratory statistical analysis tested possible different abnormalities between the $A D M C l$ and PDMCI groups. In this sessions, two ANOVAs were computed using the eLORETA LLC solutions as a dependent variable $(p<0.05)$. LLC solutions were transformed using the $\log 10$ function to have a Gaussian distribution. Furthermore, alpha variability was used as a covariate. Mauchly's test evaluated the sphericity assumption. The degrees of freedom were corrected by the Greenhouse-Geisser procedure when appropriate $(p<0.05)$. More details on the two ANOVAs are reported as next.

The first ANOVA tested the differences of interhemispheric LLC solutions between MCI groups vs. Nold group (i.e., $\mathrm{ADMCl}$ and $\mathrm{PDMCl} \neq \mathrm{Nold}$ ) and $\mathrm{ADMCl}$ group vs. PDMCl group (i.e., $A D M C l \neq P D M C l)$. The ANOVA factors were Group (Nold, $A D M C l$, and PDMCl), Band (delta, 
theta, alpha 1, alpha 2, alpha 3, beta 1, beta 2, and gamma), and ROI (frontal, central, parietal, occipital, and temporal).

The second ANOVA tested the differences of intrahemispheric LLC solutions between $\mathrm{MCl}$ groups vs. Nold group (i.e., $\mathrm{ADMCl}$ and $\mathrm{PDMCl} \neq \mathrm{Nold}$ ) and $\mathrm{ADMCl}$ group vs. $\mathrm{PDMCl}$ group (i.e., $A D M C l \neq P D M C l)$. The ANOVA factors were Group (Nold, $A D M C l$, and $P D M C l)$, Hemisphere (left and right), Band (delta, theta, alpha 1, alpha 2, alpha 3, beta 1, beta 2, and gamma), and ROI (frontal, central, parietal, occipital, temporal, and limbic).

In this statistical session, the confirmation of the primary hypothesis may require: (1) a statistically significant ANOVA effect including the factor Group $(p<0.05)$ and $(2)$ a post-hoc Duncan test indicating statistically significant $(p<0.05$, one-tailed, Bonferroni corrected) differences in the LLC solutions between $\mathrm{MCl}$ groups vs. Nold group (i.e., $\mathrm{ADMCl}$ and $\mathrm{PDMCl}$ > Nold in delta sources; $\mathrm{ADMCl}$ and $\mathrm{PDMCl}<$ Nold in alpha sources; $\mathrm{p}<0.05$, one-tailed, Bonferroni corrected). Concerning the exploratory analysis, a post-hoc Duncan test evaluated possible differences in the $L L C$ solutions between the $A D M C l$ vs. the PDMCI group (i.e., $A D M C I$ F PDMCl; $\mathrm{p}>0.05$ two-tailed, Bonferroni corrected).

The input data for the mentioned statistical analyses were controlled by the Grubbs test $(p<0.0001)$ for the presence of outliers in the distribution of the LLC solutions.

As an exploratory statistical analysis at the individual level, Spearman test evaluated the correlation between the MMSE score and LLC solutions showing statistically significant differences between the Nold and the $\mathrm{MCl}$ groups (Bonferroni corrected $\mathrm{p}<0.05$ ). The correlation analysis was performed considering all Nold, $\mathrm{ADMCl}$, and PDMCI individuals as a whole group for two reasons. On the one hand, the hypothesis was that LLC solutions from rsEEG cortical sources were correlated with the global cognitive status of seniors in general, namely including cases with both normal and impaired cognitive functions. On the other hand, the correlation study would have had a low statistical sensitivity if performed only in the separate groups, due to the very limited scatter of the MMSE scores within a given group (e.g., in Nold subjects, the MMSE score can just assume discrete values of 30,29 , and 28). To take into account the inflating effects of repetitive univariate tests, the statistical threshold was determined based on the Bonferroni correction at $p<0.05$.

Accuracy of the discrimination between the Nold, $A D M C l$, and PDMCl individuals 
For minimizing the statistical analyses and false discoveries in the present study, eLORETA LLC solutions showing statistically significant ANOVA differences $(p<0.05)$ among the three groups (i.e. effects of the factor Group and Duncan post-hoc) were used as discriminant variables for the classification of the Nold subjects and the $\mathrm{MCl}$ subjects of each group (i.e. Nold vs. ADMCl and Nold vs. PDMCI). These classifications were performed by GraphPad Prism software (GraphPad Software, Inc, California, USA) using its implementation of ROC curves (DeLong et al., 1988). The following indexes measured the results of the binary classifications: (1) Sensitivity. It measures the rate of the cases (i.e. subjects with $\mathrm{MCl}$ in the classifications of those $\mathrm{MCl}$ and Nold subjects) who were correctly classified as cases (i.e. "true positive rate" in the signal detection theory); (2) Specificity. It measures the rate of the controls (i.e. Nold subjects in the classifications of those subjects and $\mathrm{MCl}$ subjects) who were correctly classified as controls (i.e. "true negative rate" in the signal detection theory); (3) Accuracy. It is the mean between the sensitivity and specificity weighted for the number of cases and controls; and (4) AUROC curve. For sake of brevity, the AUROC curve was used as a major reference index of the global classification accuracy.

\section{Results}

Comparison of eLORETA interhemispheric LLC solutions among Nold, ADMCI, and PDMCI groups

Figure 1 shows mean values ( \pm standard error mean, SE) of the interhemispheric LLC solutions for: three groups (Nold, $\mathrm{ADMCl}$, and PDMCI), eight bands (delta, theta, alpha 1, alpha 2 , alpha 3 , beta 1 , beta 2 , and gamma), and five ROls (frontal, central, parietal, occipital, and temporal). Here the LLC solutions reflect the statistical interdependence of pairs of homologous eLORETA cortical sources between the two hemispheres, estimated from scalp rSEEG rhythms at the frequency bands of interest. In Figure 1, the profile and magnitude of the interhemispheric LLC solutions differed across the ROIs and frequency bands within and between the Nold, $\mathrm{ADMCl}$, and $\mathrm{PDMCl}$ groups, thus exploiting spatial and frequency information contents of the methodological approach.

In the Nold group as a physiological reference, dominant values of interhemispheric LLC solutions were observed in temporal (maximum), occipital, and parietal alpha 2 and alpha 3 sources. Low values of interhemispheric LLC solutions were found in the widespread delta, 
theta, and alpha 1 sources. The LLC solutions in beta 1 , beta 2 , and gamma sources were very low. Summarizing, the Nold group was characterized by a prominent interhemispheric functional connectivity between posterior cortical sources of moderate to high-frequency alpha rhythms. Compared with the Nold group, the two $\mathrm{MCl}$ groups (i.e., $\mathrm{ADMCl}$ and PDMCI) showed a similar spatial and frequency profile of interhemispheric LLC solutions but a lower magnitude. In both $\mathrm{MCl}$ groups, there was a substantial decrease of the interhemispheric LLC solutions in frontal, central, parietal, occipital, and temporal alpha 2 and alpha 3 sources. Remarkably, no sensible differences in LLC solutions can be observed between the two $\mathrm{MCl}$ groups.

Log10 transformation was used to make Gaussian the distributions of interhemispheric eLORETA LLC solutions in Nold, ADMCl, and PDMCl subjects. Kolmogorov-Smirnov test confirmed that all log10 transformed interhemispheric LLC solutions presented a Gaussian distribution in the Nold, $A D M C l$, and PDMCl groups ( $p>0.05)$. The ANOVA on $\log 10$ transformed interhemispheric eLORETA LLC solutions showed a significant interaction Group $X$ Band $X$ ROI $(F=1.4, p=0.03)$. Duncan planned post-hoc testing $(p<0.00041$ to obtain the Bonferroni correction at $p<0.05)$ revealed that the discriminant LLC pattern ADMCI and PDMCl $<$ Nold was fitted by the parietal $(p<0.00002)$, occipital $(p<0.00001)$, and temporal ( $p$ $<0.000005$ ) alpha 2 sources as well as parietal ( $<<0.00001)$, occipital ( $<<0.00001$ ), and temporal $(p<0.00001)$ alpha 3 sources. This interhemispheric effect well distinguished $A D M C l / P D M C l$ and Nold at the group level. Of note, no differences $(p>0.05)$ in the interhemispheric LLC solutions were found between the two $\mathrm{MCl}$ groups (i.e., $A D M C l$ and PDMCI).

\section{Insert here Figure 1}

Comparison of eLORETA intrahemispheric LLC solutions among Nold, ADMCI, and PDMCI groups

Figure 2 plots mean values ( $\pm \mathrm{SE}$ ) of the intrahemispheric LLC solutions for: three groups (Nold, ADMCl, and PDMCI), eight bands (delta, theta, alpha 1, alpha 2, alpha 3, beta 1, beta 2, and gamma), and five ROIs (frontal, central, parietal, occipital, and temporal). In Figure 2, the profile and magnitude of the intrahemispheric LLC solutions differed across the ROIs and 
frequency bands within and between the Nold, $\mathrm{ADMCl}$, and PDMCl groups, again exploiting spatial and frequency information contents of the methodological approach.

In the Nold group as a reference, dominant values of intrahemispheric LLC solutions were observed in temporal (maximum), occipital, and parietal alpha 2 and 3 sources while moderate values were found in central and frontal alpha 2 and 3 sources. Low values interhemispheric LLC solutions were registered in delta, theta, and alpha 1 sources in all ROIs. As for the interhemispheric LCC solutions, the intrahemispheric LLC solutions in beta 1, beta 2 , and gamma sources were very low. As for the interhemispheric functional connectivity, the Nold group was characterized by a prominent intrahemispheric functional connectivity in widespread cortical sources of moderate to high-frequency alpha rhythms.

As for the interhemispheric LLC solutions, the two $\mathrm{MCl}$ groups (i.e., $\mathrm{ADMCl}$ and $\mathrm{PDMCl}$ ) showed a similar spatial and frequency profile of intrahemispheric LLC solutions but a lower magnitude benchmarked against the Nold group. There was a substantial decrease in the intrahemispheric LLC solutions in frontal, central, parietal, occipital, and temporal alpha 2 and 3 sources. Remarkably, no differences were observed between the two $\mathrm{MCl}$ groups.

Log10 transformation was used to make Gaussian the distributions of intrahemispheric eLORETA LLC solutions in Nold, ADMCl, and PDMCl subjects. Kolmogorov-Smirnov test confirmed that all $\log 10$ transformed interhemispheric LLC solutions presented a Gaussian distribution in the Nold, $A D M C l$, and PDMCl groups ( $p>0.05$ ). The ANOVA on log10 transformed intrahemispheric eLORETA LLC solutions showed a significant interaction Group $X$ Band $(F=2.6, p=0.001)$ regardless the hemispheres (i.e., the substantial symmetry of the intrahemispheric LLC solutions in the left and the right side) and ROIs. Duncan planned posthoc testing ( $p<0.0021$ to obtain the Bonferroni correction at $p<0.05$ ) showed that the discriminant LLC pattern ADMCI and PDMCl < Nold was fitted by the global alpha 2 ( $p<$ $0.000005)$ and alpha $3(p<0.00002)$ sources. This intrahemispheric effect distinguished $A D M C l / P D M C l$ and Nold at the group level. Again, no differences $(p>0.05)$ in the intrahemispheric LLC solutions were found between the two $\mathrm{MCl}$ groups (i.e., $A D M C l$ and PDMCI).

Insert here Figure 2 
A control statistical analysis was performed to verify that the above discriminant LLC solutions were not merely due to some outliers. To this aim, the Grubbs' test $(p<0.0001)$ evaluated the presence of outliers in the data of the three groups (i.e., Nold, ADMCl, and PDMCI). The analysis was performed for the two discriminant alpha intrahemispheric LLC solutions (i.e., global alpha 2; global alpha 3) and the six discriminant alpha interhemispheric LLC solutions (i.e., parietal, occipital, and temporal alpha 2; parietal, occipital, and temporal alpha 3). No outlier was found in any group (see Figure 3 ), thus confirming the results of the main statistical analysis.

\section{Insert here Figure 3}

\section{Correlation of LLC solutions and MMSE scores across Nold, $A D M C l$, and PDMCl individuals}

As a first exploratory analysis at the individual level, Spearman test evaluated the correlation between the MMSE score, as a rough index of global cognition, and 8 LLC solutions (log10 transformed) showing statistically significant differences between the Nold and the $\mathrm{MCl}$ groups $(p<0.05)$. These LLC solutions are listed in the following: interhemispheric LLC solutions in parietal, occipital, and temporal alpha 2 and 3 sources; intrahemispheric LLC solutions in global alpha 2 and 3 sources.

A statistically significant $(p<0.00625$ to obtain the Bonferroni correction at $p<0.05)$ positive correlation was found between: (1) the interhemispheric LLC solutions in temporal alpha $2(r=0.19, p<0.004)$, occipital alpha 3 sources $(r=0.21, p<0.002)$, and the MMSE scores; (2) the intrahemispheric LLC solutions in global alpha 3 and the MMSE scores $(r=0.2$, $p<0.003)$. The higher the LLC solutions, the higher the MMSE score. Figure 4 shows the scatterplots of those 3 LLC solutions showing statistically significant correlations $(p<0.05$ corrected). It was noted the large variability in the alpha source connectivity even within the Nold group and the relatively low values of the correlation coefficients.

As a control analysis, the same correlation test was performed for any single group considered separately. No statistically significant result $(p>0.05)$ was observed, possibly due to the very limited range of the MMSE score within the single groups.

\section{Insert here Figure 4}


Classification among Nold, $A D M C I$, and PDMCI individuals based on the discriminant $L L C$ solutions

As a second exploratory analysis at the individual level, the above eight LLC solutions ( $\log 10$ transformed) showing statistically significant differences between the Nold and the $\mathrm{MCl}$ groups $(\mathrm{p}<0.05)$ were used as an input to the computation of the AUROC curves. This computation tested the ability of those LLC solutions in the classification of Nold subjects vs. $\mathrm{MCl}$ (i.e., $\mathrm{ADMCl}$ and $\mathrm{PDMCl}$ ) subjects.

Results of the classification between Nold vs. ADMCI individuals showed that only the interhemispheric LLC solutions in the temporal alpha 3 sources overcome the threshold of 0.7 of the AUROC curve, defined as a "moderate" classification rate. The interhemispheric LLC solutions in the temporal alpha 3 sources reached the following classification rate (Figure 5 top): a sensitivity of $73 \%$, a specificity of $64 \%$, an accuracy of $68.5 \%$, and an AUROC curve of 0.71 .

Concerning the classification of the Nold vs. PDMCl individuals, only the interhemispheric LLC solutions in the temporal alpha 2 sources overcome the threshold of 0.7 of the AUROC curve. The interhemispheric LLC solutions in the temporal alpha 2 sources reached the following classification rate (Figure 5 bottom): a sensitivity of $66.7 \%$, a specificity of $69.3 \%$, an accuracy of $68 \%$, and an AUROC curve of 0.72 .

Furthermore, no substantial classification accuracy between the ADMCl and PDMCI individuals was revealed at all.

\section{Insert here Figure 6}

\section{Control analyses}

In the main data analysis, alpha rhythms were divided in sub-bands based on clinical standards (International Federation of Clinical Neurophysiology Guidelines of Nuwer et al. 1999 and Guidelines of the International Pharmaco-EEG Society of Jobert et al. 2012) as well as previous neurophysiological evidence showing that dominant low- (alpha 1 and alpha 2) and high-frequency (alpha 3) alpha rhythms may have a different weight in the fluctuation of vigilance and processing of modal specific, sensorimotor or semantic information, respectively (Klimesch, 1999; Pfurtscheller and Lopes da Silva, 1999). However, it has been suggested that alpha rhythms may have global features as a whole band (International Federation of Clinical 
Neurophysiology Glossary of Nuwer et al. 1999 and Guidelines of the International PharmacoEEG Society of Kane et al., 2017). Therefore, we performed a control analysis to evaluate the differences of LLC solutions in the whole alpha band between $\mathrm{MCl}$ groups vs. Nold group (i.e., $A D M C l$ and $P D M C l \neq N$ Nold) and $A D M C l$ group vs. $P D M C l$ group (i.e., $A D M C l \neq P D M C l)$. We addressed this issue using the TF and IAF as landmarks. Firstly, the individual whole alpha band was defined as the frequency range from TF to IAF $+2 \mathrm{~Hz}$. Secondly, we computed the interhemispheric and intrahemispheric LLC solutions in the individual whole alpha band. Figure 6 showed the mean values $( \pm \mathrm{SE}$ ) of the interhemispheric (left) and intrahemispheric (right) LLC of eLORETA rsEEG cortical sources in whole alpha band for: three groups (Nold, $A D M C l$, and $P D M C l$ ) and five ROls (frontal, central, parietal, occipital, and temporal). Compared with the Nold group, the two $\mathrm{MCl}$ groups (i.e., $\mathrm{ADMCl}$ and $\mathrm{PDMCl}$ ) showed a substantial decrease of the posterior interhemispheric and widespread alpha intrahemispheric LLC solutions. Thirdly, we performed two ANOVAs using the eLORETA LLC solutions in the whole alpha band as a dependent variable $(p<0.05)$. LLC solutions were transformed using the log10 function to have a Gaussian distribution as revealed by Kolmogorov-Smirnov test (all log10 transformed LLC solutions presented a Gaussian distribution in the three groups, $p>0.05)$. Alpha variability was used as a covariate.

The first control ANOVA was focused on the differences of interhemispheric LLC solutions in the whole alpha band among Nold, ADMCl, and PDMCI. The ANOVA factors were Group (Nold, ADMCl, and PDMCl) and ROI (frontal, central, parietal, occipital, and temporal). Instead, the second control ANOVA was focused on the differences of intrahemispheric LLC among Nold, ADMCl, and PDMCI. The ANOVA factors were Group (Nold, ADMCl, and PDMCI), Hemisphere (left and right), and ROI (frontal, central, parietal, occipital, temporal, and limbic). Duncan test was used for post-hoc comparisons (Bonferroni corrected $p<0.05$ ). Specifically, we tested the following prediction: (1) a statistically significant effect including the factor Group ( $p<0.05)$ and $(2)$ a post-hoc test indicating statistically significant differences in the alpha $\mathrm{LLC}$ solutions between $\mathrm{MCl}$ groups vs. Nold group (i.e., $\mathrm{ADMCl}, \mathrm{PDMCl} \neq \mathrm{Nold} ; \mathrm{p}<0.05$ one-tailed). As an exploratory analysis, a post-hoc test tested possible significant differences in the alpha $\mathrm{LLC}$ solutions between $\mathrm{ADMCl}$ group vs. PDMCl group (i.e., $A D M C I \neq P D M C l ; p<$ 0.05 two-tailed). 
The results of the first ANOVA showed a significant interaction Group X ROI $(F=2.5, p=$ 0.01). Duncan planned post-hoc $(p<0.0033$ to obtain the Bonferroni correction at $p<0.05)$ testing revealed that the discriminant $\mathrm{LLC}$ pattern $\mathrm{ADMCl}$ and $\mathrm{PDMCl}<\mathrm{Nold}$ was fitted by the parietal ( $p<0.001)$, occipital $(p<0.00005)$, and temporal $(p<0.0001)$ alpha sources. This interhemispheric effect distinguished $\mathrm{ADMCl} / \mathrm{PDMCl}$ and Nold at the group level. No differences $(p>0.05)$ in the alpha interhemispheric LLC solutions were found between the two $\mathrm{MCl}$ groups (i.e., $\mathrm{ADMCl}$ and $\mathrm{PDMCl}$ ).

Similarly, the results of the second ANOVA showed a significant interaction Group X ROI $(F=2.9, p=0.003)$. Duncan planned post-hoc testing $(p<0.0033$ to obtain the Bonferroni correction at $\mathrm{p}<0.05)$ revealed that the discriminant LLC pattern $A D M C I$ and $P D M C I<N o l d$ was fitted by the central $(p<0.002)$, parietal ( $p<0.00003)$, occipital ( $p<0.00003)$, and temporal $(p<0.0001)$ alpha sources. This intrahemispheric effect distinguished ADMCI/PDMCI and Nold at the group level. Again, no differences $(p>0.05)$ in the alpha intrahemispheric LLC solutions were found between the two $\mathrm{MCl}$ groups (i.e., $\mathrm{ADMCl}$ and $\mathrm{PDMCl}$ ).

The present results of this control analysis suggest that the interhemispheric and intrahemispheric LLC solutions in whole alpha sources were abnormally lower in both $\mathrm{MCl}$ groups compared to the Nold group. These results also suggest that there is a global alteration of alpha rhythms in $\mathrm{ADMCl}$ and $\mathrm{PDMCl}$ patients set in resting state eyes-closed condition.

\section{Insert here Figure 6}

A second control analysis was performed to evaluate the differences of alpha intrahemispheric LLC solutions between $\mathrm{MCl}$ groups vs. Nold group (i.e., $\mathrm{ADMCl}$ and $\mathrm{PDMCl} \neq$ Nold) and $\mathrm{ADMCl}$ group vs. PDMCl group (i.e., $\mathrm{ADMCl} \neq \mathrm{PDMCl}$ ) using a higher number of cortical source pairs in line with a previous study of our group in Nold subjects and AD patients with dementia (Babiloni et al., 2016b). We considered the following cortical source pairs for the alpha 2 and alpha 3 bands and both hemispheres: frontal-central, frontal-temporal, central-temporal, frontal-parietal, central-parietal, temporal-parietal, frontal-occipital, central-occipital, temporal-occipital, and parietal-occipital. For those source pairs, the eLORETA LLC solutions were used as a dependent variable in an ANOVA design $(p<0.05)$. LLC solutions were preliminarily transformed using the log10 function to ensure a Gaussian distribution in all cases. Alpha variability was used as a covariate. The ANOVA factors were Group (Nold, ADMCl, and PDMCI), Hemisphere (left and right), Band (alpha 2 and alpha 3), 
and Pair of ROIs (frontal-central, frontal-temporal, central-temporal, frontal-parietal, centralparietal, temporal-parietal, frontal-occipital, central-occipital, temporal-occipital, and parietal-occipital). Duncan test was used for post-hoc comparisons (Bonferroni corrected $p<$ 0.05). Specifically, we tested the following predictions: (1) a statistically significant effect including the factor Group $(p<0.05)$ and $(2)$ a post-hoc test indicating statistically significant differences in the alpha intrahemispheric LLC solutions between $\mathrm{MCl}$ groups vs. Nold group (i.e., $\mathrm{ADMCl}, \mathrm{PDMCl} \neq$ Nold; $\mathrm{p}<0.05$ one-tailed). As an exploratory analysis, we tested possible differences in the alpha interhemispheric LLC solutions between $A D M C l$ group vs. PDMCI group (i.e., $\mathrm{ADMCl} \neq \mathrm{PDMCl} ; \mathrm{p}<0.05$ two-tailed).

The results showed a significant interaction Group X Pair of ROIs ( $F=3.1, p=0.00001)$, regardless the hemispheres and alpha sub-bands. Duncan planned post-hoc testing $(p<$ 0.0016 to obtain the Bonferroni correction at $p<0.05)$ revealed that the discriminant LLC pattern $A D M C l$ and PDMCI $<$ Nold was fitted by the temporal-parietal $(p<0.0001)$, centraloccipital $(p<0.0004)$, temporal-parietal $(p<0.001)$, and parietal-occipital $(p<0.000005)$ alpha sources. No differences in the alpha intrahemispheric LLC solutions were found between the two $\mathrm{MCl}$ groups (i.e., $\mathrm{ADMCl}$ and $\mathrm{PDMCl}$ ). These results suggest that both $\mathrm{MCl}$ groups exhibited abnormally lower intrahemispheric LLC solutions in temporal-parietal, centraloccipital, temporal-parietal, and parietal-occipital alpha sources. Figure 7 reports the mean values $( \pm \mathrm{SE}$ ) of the intrahemispheric LLC of eLORETA rsEEG cortical sources for three groups (Nold, $A D M C l$, and PDMCI), two alpha sub-bands (alpha 2 and alpha 3), and ten pairs of ROI (frontal-central, frontal-temporal, central-temporal, frontal-parietal, central-parietal, temporal-parietal, frontal-occipital, central-occipital, temporal-occipital, and parietaloccipital).

\section{Insert here Figure 7}

An advanced and systematic classification of Nold, $A D M C l$, and $P D M C l$ individuals on the basis of rSEEG source connectivity markers was beyond the aims of the present study. However, it may be argued that the lack of significant classifications between the $A D M C I$ and PDMCI individuals was due to a sub-optimal procedure, namely we used single features of rsEEG source connectivity, selected with statistical criteria, as inputs to ROC curve. This suboptimal procedure may not use all useful information content available in the LLC solutions. To address this issue, we performed a control analysis aimed at testing the hypothesis that 
the present $\mathrm{LLC}$ solutions were not able to discriminate between the $A D M C I$ and $P D M C I$ individuals even using an advanced methodology of classification. For this control analysis, a standard support vector machine (SVM, Cristianini and Shawe-Taylor, 2000), implemented in MATLAB and Statistics Toolbox (Release 2015a; The MathWorks, Inc., Natick, Massachusetts, United States.), was used as a mathematical classifier. One-hundred runs of classifications were performed, and the classification results were averaged across these runs to estimate mean sensitivity, specificity, and accuracy in the discrimination between the ADMCI and PDMCl individuals. The whole procedure was realized by a MATLAB script.

The application of the MATLAB script to the real LLC solutions was performed in four procedural steps, which constituted a single run.

In the first step, the two patients' groups (i.e., $A D M C l$ and $P D M C l$ ) were randomly subdivided into three parts: $40 \%$ of the $\mathrm{ADMCl}$ and $\mathrm{PDMCl}$ individuals were selected for the feature extraction from LLC solutions (featuring set), $40 \%$ of them served for the training of the SVM (training set), and the remaining $20 \%$ of them were utilized for the testing phase of the classifier (testing set).

In the second step, a standard principal component analysis (PCA), implemented in the mentioned MATLAB and Statistics Toolbox, extracted the features from practically all relevant LLC variables of the featuring set (40\% of the $A D M C l$ and $P D M C l$ individuals). Namely, we considered 3 frequency bands (i.e., delta, theta, and the mean between alpha 2 and alpha 3 ) X 10 source pairs as described in the Methods (intrahemispheric and interhemispheric LLC solutions in frontal, central, parietal, occipital, and temporal source pairs). In total, 30 LLC variables were considered for any $\mathrm{MCl}$ individual dataset. No selection based on statistical considerations was made to avoid the overfitting. The PCA provided 30 principal components (PCs) corresponding to the 30 input LLC variables. Each PC was a linear combination of the original LLC variables (minus their mean value) weighted using a set of coefficients called loadings and can be considered as a coordinate in a "multidimensional space." The 30 PCs were sorted in descending order based on the variance explained in the LLC variables. Starting from the first PC (i.e., the one responsible of the greatest percentage of the variance), a given number (" $n$ ") of PCs explained at least $80 \%$ of the total variance in the LLC variables. Let us consider an example in which " $n$ " is equal to four (e.g., the first PC explaining $40 \%$ of the variance, the second PC explaining $25 \%$ of the variance, the third PC explaining $10 \%$ of the 
variance, and the fourth PC explaining $6 \%$ of the variance $=81 \%)$. In this example, the four PCs can be considered as four new variables (i.e., four coordinates in the new "multidimensional space"), each formed by 60 values (one for any $\mathrm{MCl}$ individual of the featuring set).

In the third step, the loadings derived from the second step were used to transform the training set using the same linear combination of the featuring set, namely projecting the 30 LLC variables of the training set ( $40 \%$ of the $A D M C I$ and PDMCl individuals) into the same "multidimensional space" of the featuring set. According to the example of step 2, 30 new transformed variables ("extracted features") were computed (one for any LLC variable), each formed by 60 values (one for any $\mathrm{MCl}$ individual in the training set). However, only the first 4 transformed variables (corresponding to the first four PCs of step 2) were used as an input for the training of the SVM in the discrimination between $A D M C I$ and $P D M C l$ individuals. The trained SVM was used in the following step.

In the fourth step, the loadings derived from the second step were also used to transform the testing set using the same linear combination of the featuring set, namely projecting the $30 \mathrm{LLC}$ variables of the testing set (remaining $20 \%$ of the $\mathrm{ADMCl}$ and PDMCI individuals) into the same "multidimensional space" of the featuring set. Each of the 30 new transformed variables (one for any LLC variable) was formed by 30 values (one for any $\mathrm{MCl}$ individual in the testing set). According to the example of step 2, only the first 4 transformed variables (corresponding to the four PCs of step 2) were used as an input for testing the trained SVM in the discrimination between $\mathrm{ADMCl}$ and PDMCl individuals. The outcome of the trained SVM was reported as sensitivity, specificity, and accuracy.

The above step-wise procedure provided the following results as an average of the 100 runs: (1) the mean " $n$ " was $4.31 \pm 0.26 \mathrm{SE}$; (2) the training of the SVM showed a sensitivity of $77.41 \% \pm 5.01 \% \mathrm{SE}$, a specificity of $49.55 \% \pm 9.12 \% \mathrm{SE}$, and an accuracy of $63.48 \% \pm 7.06 \% \mathrm{SE}$; (3) the testing of the trained SVM exhibited a sensitivity of $62.32 \% \pm 2.51 \%$ SE, a specificity of $37.62 \% \pm 3.22 \% \mathrm{SE}$, and an accuracy of $49.97 \% \pm 2.86 \% \mathrm{SE}$. These results confirmed those of the main analysis, namely the LLC solutions estimated in the present study were not able to discriminate between the $\mathrm{ADMCl}$ and $\mathrm{PDMCl}$ individuals, possibly reflecting common abnormalities in the underlying neurophysiological mechanisms of the two diseases.

As a methodological remark, the MATLAB script was preliminarily validated by a simulation study in random datasets generated by a computerized procedure to mimic the 
real $30 \mathrm{LLC}$ variables for the $75 \mathrm{ADMCl}$ and $75 \mathrm{PDMCl}$ individuals of the present investigation. One dataset corresponded to 30 virtual LLC variables for any virtual $\mathrm{MCl}$ individual. For classification purposes, the above step-wise procedure (i.e., four steps) was used. Of note, this procedure was repeated for six sessions. In each session, the random datasets for the virtual $\mathrm{ADMCl}$ and $\mathrm{PDMCl}$ individuals were generated imposing pre-determined mean differences between groups in the simulated LLC variables (namely, $0 \%, 10 \%, 20 \%, 30 \%, 40 \%, 50 \%$ ). The criterion of validation was the prediction that the classification procedure by the trained SVM may provide a classification accuracy between virtual $\mathrm{ADMCl}$ and $\mathrm{PDMCl}$ individuals increasing proportionally to the mentioned mean differences (i.e., from $0 \%$ to $50 \%$ ). This prediction was confirmed by the results of the simulation study.

\section{Discussion}

The present exploratory investigation tested the hypothesis that the rsEEG cortical source connectivity (i.e., LLC solutions) may be abnormal in ADMCI and PDMCI patients. In the following sections, the present results will be discussed to emphasize that such connectivity may provide no redundant neurophysiological information about the prodromal stages of the two neurodegenerative diseases compared with rsEEG cortical source activity estimated in the same $A D M C l$ and $P D M C l$ patients in a previous reference study (Babiloni et al., 2017).

The "functional cortical connectivity" in alpha sources was abnormal in both ADMCI and PDMCl groups

An interesting finding of the present study is that posterior interhemispheric and widespread intrahemispheric LLC solutions alpha sources were lower in both ADMCI and PDMCl groups as compared to the Nold subjects. No differences in the alpha LLC solutions were found between the two $\mathrm{MCl}$ groups. This finding, obtained with individual frequency alpha sub-bands, extends previous EEG evidence showing differences in the rSEEG cortical connectivity in ADD and PDD groups benchmarked against Nold subjects (Adler et al., 2003; Andersson et al., 2008; Anghinah et al., 2000; Besthorn et al., 1994b; van Dellen et al., 2015; Dunkin et al., 1994; Fonseca et al., 2013, 2011, Jelic et al., 2000, 1997; Knott et al., 2000; Leuchter et al., 1992, 1987; Locatelli et al., 1998; Moazami-Goudarzi et al., 2008; Pogarell et al., 2005; Sloan et al., 1994). In those previous studies using fixed rsEEG frequency bands, ADD 
patients were characterized by a lower "functional cortical connectivity" estimated by the between-electrode pair coherence in alpha and beta rhythms, with a dominant abnormality in the dominant anterior-posterior axis (Adler et al., 2003; Anghinah et al., 2000; Babiloni et al., 2004, 2006a; Besthorn et al., 1994b; Blinowska et al., 2017; Dunkin et al., 1994; Fonseca et al., 2013, 2011, Jelic et al., 2000, 1997; Knott et al., 2000; Leuchter et al., 1992, 1987; Locatelli et al., 1998; Pogarell et al., 2005; Sloan et al., 1994). Similarly, previous investigations using fixed rsEEG frequency bands reported abnormalities in the intrahemispheric and interhemispheric anteroposterior alpha coherences in PD patients with cognitive deficits (Fonseca et al., 2013; Teramoto et al., 2016) and those with dementia with Lewy bodies (Dauwan et al., 2016). For the first time, the present finding unveiled that the abnormality in the alpha source connectivity can be observed even at the pre-dementia stage of AD and PD characterized by the $\mathrm{MCl}$ status, with no difference between the two patients' groups.

The "functional cortical connectivity" in alpha sources classified Nold vs. ADMCI and PDMCI individuals

Here we report the results of two exploratory analyses aimed at testing the clinical relevance of the present findings. The first analysis showed a significant positive correlation between MMSE scores (roughly reflecting global cognitive status) and interhemispheric LLC solutions in temporal alpha 2 and occipital alpha 3 sources as well as the intrahemispheric LLC solutions in global alpha 3 sources across all Nold, $A D M C l$, and PDMCl individuals as a whole group. However, even if statistically significant $(p<0.005)$, the correlation values were relatively low as variance explained (i.e., $r=0.19-0.21$ ). Furthermore, no statistically significant correlation ( $p>0.05$ ) was observed for any single group considered separately. The present findings suggest that neurophysiological mechanisms of the interdependence of cortical neural synchronization/desynchronization underpinning brain arousal and low vigilance (as reflected in the LLC solutions of this study) are only one of the determinants of global cognitive functions in human subjects. Other relevant neurophysiological mechanisms involved in cognitive information processes may be those related to selective attention, encoding and retrieval of information in long-term memory, frontal executive functions (some assisted by internal language), and others. Therefore, future studies may measure functional connectivity not only during the resting state condition (i.e., low vigilance) but also during 
attention, episodic and working memory, and other cognitive tasks. The derived EEG markers may be used as a multivariate input for linear (logistics regression) and non-linear (artificial neural networks or support vector machines) predictors of the MMSE score in Nold subjects and patients with neurodegenerative disorders. The expected results may show high correlation values and remarkable insights about the derangement of brain functions in the evolution of neurodegenerative disorders.

The second analysis showed a moderate classification accuracy of ADMCI and Nold individuals using the interhemispheric LLC solutions in the temporal alpha 3 sources (i.e., AUROC curve of 0.71 ). Finally, a moderate classification accuracy was obtained in PDMCI vs. Nold individuals using interhemispheric LLC solutions in temporal alpha 2 sources (i.e., the AUROC curve of 0.72 ). Noteworthy, those LLC solutions were not able to discriminate ADMCI vs. $\mathrm{PDMCl}$ individuals.

Those findings about the individual level are in line with previous evidence showing the following values of classification accuracy of Nold and AD individuals: (1) $1.0-0.45$ for Nold vs. ADD individuals (e.g. $1=100 \%$ ); (2) $0.92-0.78$ for $\mathrm{MCl}$ vs. ADD individuals; and (3) $0.87-0.60$ for the conversion from MCI to ADD status (Adler et al., 2003; Babiloni et al., 2016b; Bennys et al., 2001; Blinowska et al., 2017; Brassen et al., 2004; Buscema et al., 2007; Claus et al., 1999; Engedal et al., 2015; Garn et al., 2017; Huang et al., 2000; Jelic et al., 2000; Knyazev et al., 2011; Lizio et al., 2015; Missonnier et al., 2006; Nuwer, 1997).

Concerning the classification of Nold vs. PDMCl individuals, the present discrimination with 0.72 of success was lower than that reported in two studies using many discriminant rSEEG power density and connectivity measurements, namely 0.80-1.0 between PDD/DLB (dementia status) and Nold individuals (Engedal et al., 2015; Garn et al., 2017; Snaedal et al., 2012). A straightforward explanation is that the previous studies obtained a better classification accuracy as the patients suffered from a manifest dementia rather than the $\mathrm{MCl}$. To our knowledge, no previous cross-validated comparisons showed a high ability of rsEEG markers in the discrimination of $\mathrm{ADMCl}$ vs. PDMCI patients.

The "functional cortical connectivity" in delta sources was normal in both ADMCI and PDMCI groups 
Here we also report the negligible magnitude of the interhemispheric and intrahemispheric LLC solutions in delta sources estimated in the present Nold, ADMCl, and PDMCl groups. The fact that the delta source connectivity was normal in the PDMCl and the $A D M C I$ group was surprising in the light of the following pieces of preceding evidence. It was documented that LLC solutions in delta sources were higher in ADD than Nold subjects (Babiloni et al., 2016b). Furthermore, there were differences between Nold and ADD individuals in functional connectivity measurements derived from delta rhythms recorded at scalp sensors (Adler et al., 2003; Blinowska et al., 2017; Knott et al., 2000; Locatelli et al., 1998; Sankari et al., 2011). Moreover, delta coherence between electrode pairs showed higher values in PDD compared with ADD patients (Fonseca et al., 2013).

At the present early stage of the research, we cannot provide a final explanation about those contrasting results. At least in part, those discrepancies might be due to the present focus on the pre-dementia rather than the dementia stage of the AD and PD. Furthermore, to date, a clear cut distinction between $\mathrm{MCl}$ patients due to Lewy bodies, $P D$, and $A D$ is not available even if biomarkers and fine clinical and neuropsychological testing reduced misdiagnosis (Albert et al., 2011; Dubois et al., 2014; McKeith et al., 2017). Therefore, some inhomogeneity in the different impact of mixed neurodegenerative disorders in the different studies cannot be excluded. Future studies should address these issues systematically in the same database to clarify the matter.

\section{The clinical neurophysiological model}

On the whole, the present markers of "functional cortical connectivity" in alpha sources lead support to the concept that $A D$ and $P D$ patients may share a similar clinical neurophysiological mechanism contributing to a "cortical disconnection syndrome" (Bokde et al., 2009; Teipel et al., 2016), even at the pre-dementia stage of the $\mathrm{MCl}$ status.

Noteworthy, the present markers of the "functional cortical connectivity" in alpha sources were not able to differentiate the PDMCI and $A D M C l$ patients. This finding suggests that cholinergic ascending systems, which are impaired in both $A D M C l$ and $P D M C l$ groups (Bohnen et al., 2015), might play a significant role in the modulation of the "functional cortical connectivity". This "cholinergic hypothesis" is based on a bulk of previous pharmaco-rsEEG evidence. In healthy adults, a single dose of a muscarinic cholinergic antagonist (i.e., 
scopolamine) over placebo transiently increased resting state delta and theta power density while it reduced the power density at alpha and beta rhythms (Ebert and Kirch, 1998; LiemMoolenaar et al., 2011). A similar effect was also observed in Nold and ADD patients as a function of the integrity of cholinergic neurotransmission (Neufeld et al., 1994). Finally, a single dose of scopolamine deranged composite measurements of power density and coherence from delta to gamma in ADD patients kept in resting state condition (Johannsson et al., 2015; Snaedal et al., 2010).

Concerning the above speculation, less clear is the previous evidence about the effects of Acetylcholinesterase inhibitor drugs (i.e., enhancing the cholinergic tone) in ADD patients. Some studies reported a beneficial increase or a less reduction of alpha rhythms over time in ADD patients in line with the present "cholinergic" hypothesis (Agnoli et al., 1983; Babiloni et al., 2006b; Balkan et al., 2003). Furthermore, there was an increment in the alpha-theta ratio observed after a single dose of an Acetylcholinesterase inhibitor drug administered to ADD patients clinically responding to a long chronic treatment when compared to the nonresponders (Alhainen et al., 1991). However, this effect might be not specific as a beneficial effect of the cholinergic treatment in ADD patients was also observed as decreased delta (Adler and Brassen, 2001; Balkan et al., 2003; Gianotti et al., 2008; Reeves et al., 2002) and theta (Adler et al., 2004; Brassen and Adler, 2003; Gianotti et al., 2008) rhythms.

Future well-controlled pharmacological experiments are needed to have a direct measure of the correlation between alpha source functional connectivity and cholinergic transmission.

\section{Methodological remarks}

In the reference study carried out in the same Nold, ADMCI, and PDMCl populations (Babiloni et al., 2017), we discussed some methodological limitations of this retrospective and explorative study. Summarizing, these limitations include the relatively small number of the patients ( $N=75$ ) and the lack of (1) unified experimental recording protocol across the Clinical units involved, (2) harmonized hardware for EEG recordings and neuroimaging, (3) extensive neuroimaging (e.g., systematic use of Dopamine Transporter Scan, DAT-scan, in all patients), (4) extensive neuropsychological battery (e.g., Alzheimer's Disease Assessment Scale- 
cognitive subscale, ADAS-Cog) in all clinical Units, and (5) repeated clinical exams and instrumental recordings over time.

Here an additional methodological limitation is discussed. In the present study, 19 scalp electrodes (e.g., 10-20 system) were used for EEG recordings as a clinical standard in all Units of this international Consortium. Noteworthy, 10-20 system is not ideal for an optimal spatial sampling of EEG and source analysis (Liu et al., 2002; Marino et al., 2016). Rather, an optimal EEG recording may use 64-128 electrodes. However, 19 electrodes may be still acceptable as a minimum number of sensors for a cortical source estimation of eyes-closed rsEEG rhythms in patients with neurodegenerative disorders. Indeed, these rhythms are assumed to reflect a state of mental and muscular relaxation possibly associated with a diffuse cortical neural synchronization at alpha frequencies and, in those patients, a diffuse abnormal cortical neural synchronization at delta frequencies (Babiloni et al., 2016a, 2016b, 2017). This distributed pattern of cortical neural synchronization may not require mandatorily the high spatial sampling of EEG activity and fine-grain source analysis necessary to study the circumscribed functional topography of evoked- or event-related potentials (Babiloni et al., 2016a). Indeed, rsEEG rhythms may represent the summation at scalp electrodes of the oscillatory component of post-synaptic potentials generated in large masses of cortical pyramidal neurons (several squared centimetres; Nunez and Srinivasan, 2006; Srinivasan et al., 2007) as sources of electromagnetic fields. However, we are aware of the importance that future studies will perform rsEEG recordings with 64-128 electrodes to enhance the spatial resolution of source estimation and connectivity.

\section{Conclusions}

A previous reference investigation showed robust abnormalities in cortical sources of delta and alpha rhythms, as markers of brain neural "synchronization/desynchronization," in $\mathrm{ADMCl}$ and $\mathrm{PDMCl}$ patients set in the resting state condition compared to Nold subjects (Babiloni et al., 2017). Furthermore, there were some slight differences in those rhythms even between the $A D M C l$ and $P D M C l$ groups. Here we re-analyzed those original rsEEG data with the primary hypothesis that LLC solutions between cortical sources, as markers of "functional cortical connectivity," may be abnormal in ADMCl and PDMCl patients compared with Nold subjects. The analysis was performed at the individual and the group level. Noteworthy, we 
expected that such connectivity might provide no redundant neurophysiological information about the prodromal stages of the two neurodegenerative diseases compared with rsEEG cortical source activity estimated in the reference investigation (Babiloni et al., 2017).

At the group level, the findings showed that posterior interhemispheric and intrahemispheric connectivity (i.e., LLC solutions) in alpha sources was abnormally lower in both $\mathrm{ADMCl}$ and PDMCl groups when compared to the Nold group. Instead, no difference in those markers was found between the two $\mathrm{MCl}$ groups.

At the individual level, AUROC curves of LLC solutions in temporal alpha sources exhibited moderate accuracies in the classification of the Nold vs. ADMCI individuals $(0.71)$ and the Nold vs. PDMCl individuals (0.72). Again, LLC solutions were not successful in the classification of the $A D M C l$ vs. PDMCl individuals.

In contrast to previous evidence based on rsEEG cortical source activity (Babiloni et al., 2017), the findings of this study suggest similar abnormalities in widespread alpha (but not delta) source connectivity in $\mathrm{ADMCl}$ and $\mathrm{PDMCl}$ patients. This finding may reflect a common cholinergic impairment in those prodromal stages of AD and PD.

On the whole, the results of the previous reference study (Babiloni et al., 2017) and the present investigation provide a clear evidence of the complementary and no redundant information of "synchronization/desynchronization" and "connectivity" markers that can be derived by non-invasive and cost-effective techniques applied on rsEEG rhythms in $A D M C I$ and PDMCl patients.

However, some methodological limitations in this retrospective investigation (e.g., lack of harmonized experimental procedures in the participant clinical units) motivate future studies for a cross-validation of the present findings. Ideally, prospective longitudinal studies may record rsEEG data from 32-64 scalp electrodes in de-novo $A D M C I$ and $P D M C l$ patients for the extraction of the present "connectivity" markers before and after six months of treatment with Acetylcholinesterase inhibitors. These markers may be obtained with more than one procedure (i.e., LLC, isolated effective coherence, etc.; Pascua-Marqui et al., 2011, 2014), and results of these procedures may be compared within and between groups for confirmatory purposes. An important criterion to select the best procedure for rsEEG source connectivity analysis may be the ability to reduce the large variability in the alpha source connectivity in 
both Nold and $\mathrm{MCl}$ subjects and enhance the correlation coefficients with clinically relevant variables. 


\section{Conflict of Interest Statement}

The Authors declare that the research was conducted in the absence of any commercial or financial relationships that could be construed as a potential conflict of interest. 


\section{References}

Aarsland D, Litvan I, Salmon D, Galasko D, Wentzel-Larsen T, Larsen JP. Performance on the dementia rating scale in Parkinson's disease with dementia and dementia with Lewy bodies: comparison with progressive supranuclear palsy and Alzheimer's disease. J Neurol Neurosurg Psychiatry 2003;74:1215-20. doi:10.1136/jnnp.74.9.1215.

Adler G, Brassen S. Short-term rivastigmine treatment reduces EEG slow-wave power in Alzheimer patients. Neuropsychobiology 2001;43:273-6. doi:10.1159/000054902.

Adler G, Brassen S, Chwalek K, Dieter B, Teufel M. Prediction of treatment response to rivastigmine in Alzheimer's dementia. J Neurol Neurosurg Psychiatry 2004;75:292-4. doi:http://dx.doi.org/10.1136/jnnp.2003.012518.

Adler G, Brassen S, Jajcevic A. EEG coherence in Alzheimer's dementia. J Neural Transm 2003;110:1051-8. doi:10.1007/s00702-003-0024-8.

Agnoli A, Martucci N, Manna V, Conti L, Fioravanti M. Effect of cholinergic and anticholinergic drugs on shortterm memory in Alzheimer's dementia: a neuropsychological and computerized electroencephalographic study. Clin Neuropharmacol 1983;6:311-23.

Albert MS, DeKosky ST, Dickson D, Dubois B, Feldman HH, Fox NC, et al. The diagnosis of mild cognitive impairment due to Alzheimer's disease: recommendations from the National Institute on Aging-Alzheimer's Association workgroups on diagnostic guidelines for Alzheimer's disease. Alzheimers Dement 2011;7:270-9. doi:10.1016/j.jalz.2011.03.008.

Alhainen K, Partanen J, Reinikainen K, Laulumaa V, Soininen H, Airaksinen M, et al. Discrimination of tetrahydroaminoacridine responders by a single dose pharmaco-EEG in patients with Alzheimer's disease. Neurosci Lett 1991;127:113-6. doi:10.1016/0304-3940(91)90907-B.

Andersson M, Hansson O, Minthon L, Rosén I, Londos E. Electroencephalogram variability in dementia with lewy bodies, Alzheimer's disease and controls. Dement Geriatr Cogn Disord 2008;26:284-90. doi:10.1159/000160962.

Anghinah R, Kanda PA, Jorge MS, Lima EE, Pascuzzi L, Melo AC. Alpha band coherence analysis of EEG in healthy adult's and Alzheimer's type dementia patients. Arq Neuropsiquiatr 2000;58:272-5. doi:S0004282X2000000200011 [pii].

Babiloni C, Ferri R, Moretti D V, Strambi A, Binetti G, Dal Forno G, et al. Abnormal fronto-parietal coupling of brain rhythms in mild Alzheimer's disease: a multicentric EEG study. Eur J Neurosci 2004;19:2583-90. doi:10.1111/j.0953-816X.2004.03333.x.

Babiloni C, Ferri R, Binetti G, Cassarino A, Forno GD, Ercolani M, et al. Fronto-parietal coupling of brain rhythms in mild cognitive impairment: A multicentric EEG study. Brain Res Bull 2006a;69:63-73. doi:10.1016/j.brainresbull.2005.10.013.

Babiloni C, Cassetta E, Dal Forno G, Del Percio C, Ferreri F, Ferri R, et al. Donepezil effects on sources of cortical rhythms in mild Alzheimer's disease: Responders vs. Non-Responders. Neuroimage 2006b;31:1650-65. doi:10.1016/j.neuroimage.2006.02.015.

Babiloni C, Ferri R, Binetti G, Vecchio F, Frisoni GB, Lanuzza B, et al. Directionality of EEG synchronization in Alzheimer's disease subjects. Neurobiol Aging 2009;30:93-102. doi:10.1016/j.neurobiolaging.2007.05.007.

Babiloni C, Frisoni GB, Vecchio F, Pievani M, Geroldi C, De Carli C, et al. Global functional coupling of resting EEG rhythms is related to white-matter lesions along the cholinergic tracts in subjects with amnesic mild cognitive impairment. J Alzheimer's Dis 2010;19:859-71. doi:10.3233/JAD-2010-1290.

Babiloni C, Lizio R, Marzano N, Capotosto P, Soricelli A, Triggiani Al, et al. Brain neural synchronization and functional coupling in Alzheimer's disease as revealed by resting state EEG rhythms. Int J Psychophysiol 
2016a;103:88-102. doi:10.1016/j.ijpsycho.2015.02.008.

Babiloni C, Triggiani Al, Lizio R, Cordone S, Tattoli G, Bevilacqua V, Soricelli A, Ferri R, Nobili F, Gesualdo L, MillánCalenti JC, Buján A, Tortelli R, Cardinali V, Barulli MR, Giannini A, Spagnolo P, Armenise S, Buenza G, Scianatico G, Logroscino G, Frisoni GB, Del Percio C. Classification of Single Normal and Alzheimer's Disease Individuals from Cortical Sources of Resting State EEG Rhythms. Front Neurosci. 2016b; 23:10-47.

Babiloni C, Del Percio C, Lizio R, Noce G, Cordone S, Lopez S, Soricelli A, Ferri R, Pascarelli MT, Nobili F, Arnaldi D, Famà F, Aarsland D, Orzi F, Buttinelli C, Giubilei F, Onofrj M, Stocchi F, Stirpe P, Fuhr P, Gschwandtner U, Ransmayr G, Caravias G, Garn H, Sorpresi F, Pievani M, D'Antonio F, De Lena C, Güntekin B, Hanoğlu L, Başar E, Yener G, Emek-Savaş DD, Triggiani Al, Franciotti R, Frisoni GB, Bonanni L, De Pandis MF. Abnormalities of Cortical Neural Synchronization Mechanisms in Subjects with Mild Cognitive Impairment due to Alzheimer's and Parkinson's Diseases: An EEG Study.J Alzheimers Dis. 2017;59(1):339-358. doi: 10.3233/JAD-160883.

Balkan S, Yaraş N, Mihçi E, Dora B, Ağar A, Yargiçoğlu P. Effect of donepezil on EEG spectral analysis in Alzheimer's disease. Acta Neurol Belg 2003;103:164-9. doi:10.1162/jocn.1996.8.6.551.

Bennys K, Rondouin G, Vergnes C, Touchon J. Diagnostic value of quantitative EEG in Alzheimer's disease. Clin Neurophysiol 2001;31:153-60. doi:Doi: 10.1016/s0987-7053(01)00254-4.

Besthorn C, Förstl H, Geiger-Kabisch C, Sattel H, Gasser T, Schreiter-Gasser U. EEG coherence in Alzheimer disease. Electroencephalogr Clin Neurophysiol 1994a;90:242-5. doi:10.1016/0013-4694(94)90095-7.

Besthorn C, Förstl H, Geiger-Kabisch C, Sattel H, Gasser T, Schreiter-Gasser U, et al. EEG coherence in Alzheimer disease. Electroencephalogr Clin Neurophysiol 1994b;90:242-5. doi:10.1016/0013-4694(94)90095-7.

Blinowska KJ, Rakowski F, Kaminski M, De Vico Fallani F, Del Percio C, Lizio R, et al. Functional and effective brain connectivity for discrimination between Alzheimer's patients and healthy individuals: A study on resting state EEG rhythms. Clin Neurophysiol 2017;128:667-80. doi:10.1016/j.clinph.2016.10.002.

Bohnen NI, Albin RL, Müller MLTM, Petrou M, Kotagal V, Koeppe R a, et al. Frequency of Cholinergic and Caudate Nucleus Dopaminergic Deficits Across the Predemented Cognitive Spectrum of Parkinson Disease and Evidence of Interaction Effects. JAMA Neurol 2015;72:194-200. doi:10.1001/jamaneurol.2014.2757.

Bokde ALW, Ewers M, Hampel H. Assessing neuronal networks: Understanding Alzheimer's disease. Prog Neurobiol 2009;89:125-33. doi:10.1016/j.pneurobio.2009.06.004.

Brassen S, Adler G. Short-term Effects of Acetylcholinesterase Inhibitor Treatment on EEG and Memory Performance in Alzheimer Patients: An Open, Controlled Trial. Pharmacopsychiatry 2003;36:304-8. doi:10.1055/s-2003-45118.

Brassen S, Braus DF, Weber-Fahr W, Tost H, Moritz S, Adler G. Late-onset depression with mild cognitive deficits: Electrophysiological evidences for a preclinical dementia syndrome. Dement Geriatr Cogn Disord 2004;18:2717. doi:10.1159/000080028.

Brown LM, Schinka JA. Development of initial validation of a 15-item informant version of the Geriatric Depression Scale. Int J Geriatr Psychiatry 2005;20:911-8. doi:10.1002/gps.1375.

Buscema M, Rossini PM, Babiloni C, Grossi E. The IFAST model, a novel parallel nonlinear EEG analysis technique, distinguishes mild cognitive impairment and Alzheimer's disease patients with high degree of accuracy. Artif Intell Med 2007;40:127-41. doi:10.1016/j.artmed.2007.02.006.

Buter TC, Van Den Hout A, Matthews FE, Larsen JP, Brayne C, Aarsland D. Dementia and survival in Parkinson disease: A 12-year population study. Neurology 2008;70:1017-22. doi:10.1212/01.wnl.0000306632.43729.24.

Canuet L, Tellado I, Couceiro V, Fraile C, Fernandez-Novoa L, Ishii R, et al. Resting-State Network Disruption and 
APOE Genotype in Alzheimer's Disease: A lagged Functional Connectivity Study. PLoS One $2012 ; 7$. doi:10.1371/journal.pone.0046289.

Claus JJ, Strijers RLM, Jonkman EJ, Ongerboer De Visser BW, Jonker C, Walstra GJM, et al. The diagnostic value of electroencephalography in mild senile Alzheimer's disease. Clin Neurophysiol 1999;110:825-32.

Cristianini, N., and Shawe-Taylor, J. C. An Introduction to Support Vector Machines and Other KernelBased Learning Methods. Cambridge, UK: Cambridge University Press, 2000.

D’Amelio M, Rossini PM. Brain excitability and connectivity of neuronal assemblies in Alzheimer's disease: From animal models to human findings. Prog Neurobiol 2012;99:42-60. doi:10.1016/j.pneurobio.2012.07.001.

Dauwan M, van Dellen E, van Boxtel L, van Straaten ECW, de Waal H, Lemstra AW, et al. EEG-directed connectivity from posterior brain regions is decreased in dementia with Lewy bodies: A comparison with Alzheimer's disease and controls. Neurobiol Aging 2016;41:122-9. doi:10.1016/j.neurobiolaging.2016.02.017.

Dauwels J, Vialatte F, Latchoumane C, Jeong J, Cichocki A. EEG synchrony analysis for early diagnosis of Alzheimer's disease: a study with several synchrony measures and EEG data sets. Conf Proc IEEE Eng Med Biol Soc 2009;2009:2224-7. doi:10.1109/IEMBS.2009.5334862.

Dauwels J, Vialatte F, Musha T, Cichocki A. A comparative study of synchrony measures for the early diagnosis of Alzheimer's disease based on EEG. Neuroimage 2010;49:668-93. doi:10.1016/j.neuroimage.2009.06.056.

van Dellen E, de Waal H, van der Flier WM, Lemstra AW, Slooter AJC, Smits LL, et al. Loss of EEG Network Efficiency Is Related to Cognitive Impairment in Dementia With Lewy Bodies. Mov Disord 2015;30:1785-93. doi:10.1002/mds.26309.

DeLong ER, DeLong DM, Clarke-Pearson DL. Comparing the areas under two or more correlated receiver operating characteristic curves: a nonparametric approach. Biometrics 1988;44:837-45. doi:10.2307/2531595.

Dubois B, Feldman HH, Jacova C, Hampel H, Molinuevo JL, Blennow K, et al. Advancing research diagnostic criteria for Alzheimer's disease: the IWG-2 criteria. Lancet Neurol 2014;13:614-29. doi:10.1016/S1474-4422(14)700900 .

Dubois B, Pillon B. Cognitive deficits in Parkinson's disease. J Neurol 1996;244:2-8. doi:10.1007/PL00007725.

Dunkin JJ, Leuchter AF, Newton TF, Cook IA. Reduced EEG coherence in dementia: State or trait marker? Biol Psychiatry 1994;35:870-9. doi:10.1016/0006-3223(94)90023-X.

Ebert U, Kirch W. Scopolamine model of dementia: Electroencephalogram findings and cognitive performance. Eur J Clin Invest 1998;28:944-9. doi:10.1046/j.1365-2362.1998.00393.x.

Emre M, Aarsland D, Brown R, Burn DJ, Duyckaerts C, Mizuno Y, et al. Clinical diagnostic criteria for dementia associated with Parkinson's disease. Mov Disord 2007;22:1689-707. doi:10.1002/mds.21507.

Engedal K, Snaedal J, Hoegh P, Jelic V, Bo Andersen B, Naik M, et al. Quantitative EEG Applying the Statistical Recognition Pattern Method: A Useful Tool in Dementia Diagnostic Workup. Dement Geriatr Cogn Disord 2015;40:1-12. doi:10.1159/000381016.

Fahn S, Elton R. Unified Parkinson's Disease Rating Scale. Recent Dev. Park. Dis., 1987, p. 153-63.

Folstein MF, Folstein SE, McHugh PR. "Mini-mental state". A practical method for grading the cognitive state of patients for the clinician. J Psychiatr Res 1975;12:189-98. doi:0022-3956(75)90026-6 [pii].

Fonseca LC, Tedrus GM a S, Carvas PN, Machado ECF a. Comparison of quantitative EEG between patients with Alzheimer's disease and those with Parkinson's disease dementia. Clin Neurophysiol 2013;124:1970-4. 
doi:10.1016/j.clinph.2013.05.001.

Fonseca LC, Tedrus GMAS, Prandi LR, Almeida AM, Furlanetto DS. Alzheimer's disease: relationship between cognitive aspects and power and coherence EEG measures. Arq Neuropsiquiatr 2011;69:875-81. doi:10.1590/S0004-282X2011000700005.

Garn H, Coronel C, Waser M, Caravias G, Ransmayr G. Differential diagnosis between patients with probable Alzheimer's disease, Parkinson's disease dementia, or dementia with Lewy bodies and frontotemporal dementia, behavioral variant, using quantitative electroencephalographic features. J Neural Transm 2017;124:569-81. doi:10.1007/s00702-017-1699-6.

Gelb DJ, Oliver E, Gilman S. Diagnostic criteria for Parkinson disease. ArchNeurol 1999;56:33-9.

Geser F, Wenning GK, Poewe W, McKeith I. How to diagnose dementia with Lewy bodies: state of the art. Mov Disord 2005;20 Suppl 1:S11-20. doi:10.1002/mds.20535.

Gianotti LRR, Künig G, Faber PL, Lehmann D, Pascual-Marqui RD, Kochi K, et al. Rivastigmine effects on EEG spectra and three-dimensional LORETA functional imaging in Alzheimer's disease. Psychopharmacology (Berl) 2008;198:323-32. doi:10.1007/s00213-008-1111-1.

Hoehn MM, Yahr MD. Parkinsonism: onset, progression, and mortality. Neurology 1967;57:318 and 16 pages following. doi:10.1212/WNL.17.5.427.

Huang C, Wahlund L-O, Dierks T, Julin P, Winblad B, Jelic V. Discrimination of Alzheimer's disease and mild cognitive impairment by equivalent EEG sources: a cross-sectional and longitudinal study. Clin Neurophysiol 2000;111:1961-7. doi:10.1016/S1388-2457(00)00454-5.

Huber SJ, Shuttleworth EC, Freidenberg DL. Neuropsychological differences between the dementias of Alzheimer's and Parkinson's diseases. ArchNeurol 1989;46:1287-91. doi:10.1001/archneur.1989.00520480029015.

Hughes TA, Ross HF, Musa S, Bhattacherjee S, Nathan RN, Mindham RHS, et al. A 10-year study of the incidence of and factors predicting dementia in Parkinson's disease. Neurology 2000;54:1596-603. doi:10.1212/WNL.54.8.1596.

Jelic V, Johansson S-EE, Almkvist O, Shigeta M, Julin P, Nordberg A, et al. Quantitative electroencephalography in mild cognitive impairment: Longitudinal changes and possible prediction of Alzheimer's disease. Neurobiol Aging 2000;21:533-40. doi:10.1016/S0197-4580(00)00153-6.

Jelic V, Julin P, Shigeta M, Nordberg a, Lannfelt L, Winblad B, et al. Apolipoprotein E epsilon4 allele decreases functional connectivity in Alzheimer's disease as measured by EEG coherence. J Neurol Neurosurg Psychiatry 1997;63:59-65. doi:10.1136/jnnp.63.1.59.

Jelic V, Shigeta M, Julin P, Almkvist O, Winblad B, Wahlund LO. Quantitative electroencephalography power and coherence in Alzheimer's disease and mild cognitive impairment. Dementia 1996;7:314-23.

Johannsson M, Snaedal J, Johannesson GH, Gudmundsson TE, Johnsen K. The acetylcholine index: An electroencephalographic marker of cholinergic activity in the living human brain applied to Alzheimer's disease and other dementias. Dement Geriatr Cogn Disord 2015;39:132-42. doi:10.1159/000367889.

Kane N, Acharya J, Benickzy S, Caboclo L, Finnigan S, Kaplan PW, Shibasaki H, Pressler R, van Putten MJAM. A revised glossary of terms most commonly used by clinical electroencephalographers and updated proposal for the report format of the EEG findings. Revision 2017. Clin. Neurophysiol. Practice (2017), http://dx.doi.org/10.1016/j.cnp.2017.07.002.

Klimesch W. EEG alpha and theta oscillations reflect cognitive and memory performance: a review and analysis. 
Brain Res Brain Res Rev 1999;29:169-95.

Klimesch W. EEG alpha and theta oscillations reflect cognitive and memory performance: A review and analysis. Brain Res Rev 1999;29:169-95. doi:10.1016/S0165-0173(98)00056-3.

Klimesch W. Memory processes, brain oscillations and EEG synchronization. Int J Psychophysiol 1996;24:61-100. doi:10.1016/S0167-8760(96)00057-8.

Klimesch W, Doppelmayr M, Russegger H, Pachinger T, Schwaiger J. Induced alpha band power changes in the human EEG and attention. Neurosci Lett 1998;244:73-6. doi:10.1016/S0304-3940(98)00122-0.

Klimesch W, Doppelmayr M, Schimke H, Pachinger T. Alpha frequency, reaction time, and the speed of processing information. J Clin Neurophysiol 1996;13:511-8.

Knott V, Mohr E, Mahoney C, llivitsky V. Electroencephalographic coherence in Alzheimer's disease: comparisons with a control group and population norms. J Geriatr Psychiatry Neurol 2000;13:1-8. doi:10.1177/089198870001300101.

Knyazev GG, Slobodskoj-Plusnin JY, Bocharov A V, Pylkova L V. The default mode network and EEG $\alpha$ oscillations: an independent component analysis. Brain Res 2011;1402:67-79. doi:10.1016/j.brainres.2011.05.052.

Leuchter a F, Newton TF, Cook I a, Walter DO, Rosenberg-Thompson S, Lachenbruch P a. Changes in brain functional connectivity in Alzheimer-type and multi-infarct dementia. Brain 1992;115:1543-61. doi:10.1093/brain/115.5.1543.

Leuchter AF, Dunkin JJ, Lufkin RB, Anzai Y, Cook IA, Newton TF. Effect of white matter disease on functional connections in the aging brain. J Neurol Neurosurg Psychiatry 1994;57:1347-54. doi:10.1136/jnnp.57.11.1347.

Leuchter AF, Spar JE, Walter DO, Weiner H. Electroencephalographic spectra and coherence in the diagnosis of Alzheimer's-type and multi-infarct dementia. A pilot study. ArchGenPsychiatry 1987;44:993-8. doi:10.1001/archpsyc.1987.01800230073012.

Levy G, Tang MX, Cote LJ, Louis ED, Alfaro B, Mejia H, et al. Motor impairment in PD: relationship to incident dementia and age. Neurology 2000;55:539-44. doi:10.1212/WNL.55.4.539.

Liem-Moolenaar M, de Boer P, Timmers M, Schoemaker RC, van Hasselt JGC, Schmidt S, et al. Pharmacokineticpharmacodynamic relationships of central nervous system effects of scopolamine in healthy subjects. Br J Clin Pharmacol 2011;71:886-98. doi:10.1111/j.1365-2125.2011.03936.x.

Litvan I, Aarsland D, Adler CH, Goldman JG, Kulisevsky J, Mollenhauer B, et al. MDS task force on mild cognitive impairment in Parkinson's disease: Critical review of PD-MCl. Mov Disord 2011;26:1814-24. doi:10.1002/mds.23823.

Liu AK, Dale AM, Belliveau JW. Monte Carlo simulation studies of EEG and MEG localization accuracy. Hum Brain Mapp. 2002 May;16(1):47-62.

Lizio R, Del Percio C, Marzano N, Soricelli A, Yener GGGG, Başar E, et al. Neurophysiological assessment of Alzheimer's disease individuals by a single electroencephalographic marker. J Alzheimers Dis 2015;49:159-77. doi:10.3233/JAD-143042.

Locatelli T, Cursi M, Liberati D, Franceschi M, Comi G. EEG coherence in Alzheimer's disease. Electroencephalogr Clin Neurophysiol 1998;106:229-37. doi:10.1016/S0013-4694(97)00129-6.

Marino M, Liu Q, Brem S, Wenderoth N, Mantini D. Automated detection and labeling of high-density EEG electrodes from structural MR images. J Neural Eng. 2016 Oct;13(5):056003. 
McKeith IG, Dickson DW, Lowe J, Emre M, O’Brien JT, Feldman H, et al. Diagnosis and management of dementia with Lewy bodies - Third report of the DLB consortium. Neurology 2005;65:1455. doi:10.1212/01.wnl.0000224698.67660.45.

McKeith IG, Galasko D, Kosaka K, Perry EK, Dickson DW, Hansen L a, et al. Consensus guidelines for the clinical and pathologic diagnosis of dementia with Lewy bodies (DLB): report of the consortium on DLB international workshop. Neurology 1996;47:1113-24. doi:10.1212/WNL.47.5.1113.

McKeith IG, Boeve BF, Dickson DW, Halliday G, Taylor JP, Weintraub D, Aarsland D, Galvin J, Attems J, Ballard CG, Bayston A, Beach TG, Blanc F, Bohnen N, Bonanni L, Bras J, Brundin P, Burn D, Chen-Plotkin A, Duda JE, El-Agnaf O, Feldman H, Ferman TJ, Ffytche D, Fujishiro H, Galasko D, Goldman JG, Gomperts SN, Graff-Radford NR, Honig LS, Iranzo A, Kantarci K, Kaufer D, Kukull W, Lee VMY, Leverenz JB, Lewis S, Lippa C, Lunde A, Masellis M, Masliah E, McLean P, Mollenhauer B, Montine TJ, Moreno E, Mori E, Murray M, O'Brien JT, Orimo S, Postuma RB, Ramaswamy S, Ross OA, Salmon DP, Singleton A, Taylor A, Thomas A, Tiraboschi P, Toledo JB, Trojanowski JQ, Tsuang D, Walker Z, Yamada M, Kosaka K. Diagnosis and management of dementia with Lewy bodies: Fourth consensus report of the DLB Consortium. Neurology. 2017 Jul 4;89(1):88-100.

Missonnier P, Gold G, Herrmann FR, Fazio-Costa L, Michel JP, Deiber MP, et al. Decreased theta event-related synchronization during working memory activation is associated with progressive mild cognitive impairment. Dement Geriatr Cogn Disord 2006;22:250-9. doi:10.1159/000094974.

Moazami-Goudarzi M, Sarnthein J, Michels L, Moukhtieva R, Jeanmonod D. Enhanced frontal low and high frequency power and synchronization in the resting EEG of parkinsonian patients. Neuroimage 2008;41:985-97. doi:10.1016/j.neuroimage.2008.03.032.

Moretti D V, Babiloni F, Carducci F, Cincotti F, Remondini E, Rossini PM, et al. Computerized processing of EEGEOG-EMG artifacts for multi-centric studies in EEG oscillations and event-related potentials. Int J Psychophysiol 2003;47:199-216.

Morris JC. The Clinical Dementia Rating (CDR): current version and scoring rules. Neurology 1993;43:2412-4. doi:10.1212/WNL.43.11.2412-a.

Neufeld MY, Rabey MJ, Parmet Y, Sifris P, Treves TA, Korczyn AD. Effects of a single intravenous dose of scopolamine on the quantitative EEG in Alzheimer's disease patients and age-matched controls. Electroencephalogr Clin Neurophysiol 1994;91:407-12. doi:10.1016/0013-4694(94)90162-7.

Nuwer MR, Lehmann D, da Silva FL, Matsuoka S, Sutherling W, Vibert JF. IFCN guidelines for topographic and frequency analysis of EEGs and EPs.The International Federation of Clinical Neurophysiology. Electroencephalogr Clin Neurophysiol Suppl. 1999;52:15-20.

Nunez PL and Srinivasan R. Electric Fields of the Brain: The Neurophysics of EEG (2nd Ed), New York: Oxford University Press, 2006.

Nuwer M. Assessment of digital EEG, quantitative EEG, and EEG brain mapping: report of the American Academy of Neurology and the American Clinical Neurophysiology Society. Neurology 1997;49:277-92.

Pascual-Marqui RD. Discrete, 3D distributed, linear imaging methods of electric neuronal activity. Part 1: exact, zero error localization. Clin Neurophysiol 2007a;112:845-52. doi:10.1016/S1388-2457(00)00546-0.

Pascual-Marqui RD. Instantaneous and lagged measurements of linear and nonlinear dependence between groups of multivariate time series: frequency decomposition. arXiv:07111455 [statME] 2007b:1-18.

Pascual-Marqui RD. Coherence and phase synchronization: generalization to pairs of multivariate time series, and removal of zero-lag contributions. arXiv Prepr arXiv07061776 2007c:1-12. 
Pascual-Marqui RD, Lehmann D, Koukkou M, Kochi K, Anderer P, Saletu B, et al. Assessing interactions in the brain with exact low-resolution electromagnetic tomography. Philos Trans R Soc London A Math Phys Eng Sci 2011;369:3768-84. doi:10.1098/rsta.2011.0081.

Pascual-Marqui RD, Biscay RJ, Bosch-Bayard J, Lehmann D, Kochi K, Kinoshita T, Yamada N, Sadato N. Assessing direct paths of intracortical causal information flow of oscillatory activity with the isolated effective coherence (iCoh). Front Hum Neurosci. 2014 Jun 20;8:448.

Pievani M, de Haan W, Wu T, Seeley WW, Frisoni GB. Functional network disruption in the degenerative dementias. Lancet Neurol 2011;10:829-43. doi:10.1016/S1474-4422(11)70158-2.

Pogarell O, Teipel SJ, Juckel G, Gootjes L, Möller T, Bürger K, et al. EEG coherence reflects regional corpus callosum area in Alzheimer's disease. J Neurol Neurosurg Psychiatry 2005;76:109-11. doi:10.1136/jnnp.2004.036566.

Pollok B, Kamp D, Butz M, Wojtecki L, Timmermann L, Südmeyer M, et al. Increased SMA-M1 coherence in Parkinson's disease - Pathophysiology or compensation? Exp Neurol 2013;247:178-81. doi:10.1016/j.expneurol.2013.04.013.

Prince MJ, Wimo A, Guerchet MM, Ali GC, Wu Y-T, Prina M. World Alzheimer Report 2015 - The Global Impact of Dementia. Alzheimer's Disease International; 2015.

Reeves RR, Struve FA, Patrick G. The effects of donepezil on quantitative EEG in patients with Alzheimer's disease. Clin Electroencephalogr 2002;33:93-6. doi:10.1177/155005940203300209.

Rosen WG, Terry RD, Fuld PA, Katzman R, Peck A. Pathological verification of ischemic score in differentiation of dementias. Ann Neurol 1980;7:486-8. doi:10.1002/ana.410070516.

Sankari Z, Adeli H, Adeli A. Intrahemispheric, interhemispheric, and distal EEG coherence in Alzheimer's disease. Clin Neurophysiol 2011;122:897-906. doi:10.1016/j.clinph.2010.09.008.

Silberstein P, Pogosyan A, Kühn AA, Hotton G, Tisch S, Kupsch A, et al. Cortico-cortical coupling in Parkinson's disease and its modulation by therapy. Brain 2005;128:1277-91. doi:10.1093/brain/awh480.

Sloan EP, Fenton GW, Kennedy NSJ, MacLennan JM. Neurophysiology and SPECT cerebral blood flow patterns in dementia. Electroencephalogr Clin Neurophysiol 1994;91:163-70. doi:10.1016/0013-4694(94)90066-3.

Snaedal J, Johannesson GH, Gudmundsson TE, Blin NP, Emilsdottir AL, Einarsson B, et al. Diagnostic Accuracy of Statistical Pattern Recognition of Electroencephalogram Registration in Evaluation of Cognitive Impairment and Dementia. Dement Geriatr Cogn Disord 2012;34:51-60. doi:10.1159/000339996.

Snaedal J, Johannesson GH, Gudmundsson TE, Gudmundsson S, Pajdak TH, Johnsen K. The use of EEG in Alzheimer's disease, with and without scopolamine - A pilot study. Clin Neurophysiol 2010;121:836-41. doi:10.1016/j.clinph.2010.01.008.

Srinivasan R, Winter WR, Ding J, Nunez PL. EEG and MEG coherence: measures of functional connectivity at distinct spatial scales of neocortical dynamics. J Neurosci Methods. 2007 Oct 15;166(1):41-52.

Teipel S, Grothe MJ, Zhou J, Sepulcre J, Dyrba M, Sorg C, et al. Measuring Cortical Connectivity in Alzheimer's Disease as a Brain Neural Network Pathology: Toward Clinical Applications. J Int Neuropsychol Soc 2016;22:13863. doi:10.1017/S1355617715000995.

Teramoto H, Morita A, Ninomiya S, Akimoto T, Shiota H, Kamei S. Relation between Resting State Front-Parietal EEG Coherence and Executive Function in Parkinson's Disease. Biomed Res Int 2016;2016. doi:10.1155/2016/2845754.

Tóth B, File B, Boha R, Kardos Z, Hidasi Z, Gaál ZA, et al. EEG network connectivity changes in mild cognitive 
impairment - Preliminary results. Int J Psychophysiol 2014;92:1-7. doi:10.1016/j.ijpsycho.2014.02.001.

Walker Z, Possin KL, Boeve BF, Aarsland D. Lewy body dementias. Lancet 2015;386:1683-97. doi:10.1016/S01406736(15)00462-6.

Wechsler D. Manual for Wechsler Memory Scale - Revised. 1987. doi:PCA-Converted \#56.

Wolters EC. Intrinsic and extrinsic psychosis in Parkinson's disease. J Neurol 2001;248 Suppl:III22-7. doi:10.1007/PL00007822. 


\section{Table legends}

Table 1. Mean values ( \pm standard error mean, SE) of the demographic and clinical data and results of their statistical comparisons $(p<0.05)$ in the groups of normal elderly (Nold) subjects and patients with mild cognitive impairment due to Alzheimer's (ADMCI) and Parkinson's $(\mathrm{PDMCl})$ diseases. Legend: $\mathrm{MMSE}=$ Mini Mental State Evaluation; $\mathrm{M} / \mathrm{F}=$ males $/$ females; $\mathrm{n} . \mathrm{s}$. $=$ not significant $(p>0.05)$. 


\section{Figure legends}

Figure 1. Mean values ( \pm SE) of the interhemispheric lagged linear connectivity (LLC) of eLORETA resting state electroencephalographic (rSEEG) cortical sources for three groups (Nold, ADMCl, PDMCl), eight bands (delta, theta, alpha 1, alpha 2, alpha 3, beta 1, beta 2, gamma), and five ROls (frontal, central, parietal, occipital, temporal).

Figure 2. Mean values ( $\pm \mathrm{SE}$ ) of the intrahemispheric lagged linear connectivity (LLC) of eLORETA rsEEG cortical sources for three groups (Nold, ADMCl, PDMCl), eight bands (delta, theta, alpha 1 , alpha 2 , alpha 3 , beta 1 , beta 2 , gamma), and five ROIs (frontal, central, parietal, occipital, temporal).

Figure 3. Individual values of the interhemispheric and intrahemispheric LLC $(\log 10$ transformed) of eLORETA rsEEG cortical sources showing statistically significant $(p<0.05)$ differences among the Nold, $A D M C l$, and PDMCl groups (i.e., interhemispheric parietal, occipital, and temporal alpha 2; interhemispheric parietal, occipital, and temporal alpha 3; intrahemispheric global alpha 2; intrahemispheric global alpha 3). Noteworthy, the Grubbs' test showed no outliers from those individual values of the LLC of eLORETA rSEEG cortical sources (arbitrary threshold of $p<0.0001$ ).

Figure 4. Scatterplots showing the correlation between the LLC (log10 transformed) of alpha 2 cortical sources and the MMSE score in the Nold, ADMCl, and PDMCl subjects as a whole group. The Spearman test evaluated the hypothesis of a correlation these LLC and MMSE variables (Bonferroni corrected $p<0.05$ ). The $r$ and $p$ values are reported within the diagrams.

Figure 5. (Top): Receiver operating characteristic (ROC) curve illustrating the classification of the $A D M C l$ and Nold individuals based on interhemispheric LLC in temporal alpha 3 cortical sources. The area under the ROC (AUROC) curve was 0.71 indicating a moderate classification accuracy of the $A D M C l$ and Nold individuals. (Bottom): ROC curve illustrating the classification of the PDMCl and Nold individuals based on the interhemispheric LLC in temporal alpha 2 cortical sources. The AUROC was 0.72 indicating a moderate classification accuracy of the PDD and Nold individuals.

Figure 6. Mean values ( \pm SE) of the interhemispheric (left) and intrahemispheric (right) LLC of eLORETA rsEEG cortical sources in whole alpha band for: (1) three Groups (Nold, ADMCl, and PDMCI) and (2) five ROI (frontal, central, parietal, occipital, and temporal).

Figure 7. Mean values ( \pm SE) of the intrahemispheric LLC solutions of eLORETA rsEEG cortical sources for the three groups ( $\mathrm{Nold}, \mathrm{ADMCl}$, and PDMCI), the two alpha sub-bands (alpha 2 and alpha 3 ), and (2) the ten pairs of ROIs (frontal-central, frontal-temporal, central-temporal, frontal-parietal, central-parietal, temporal-parietal, frontal-occipital, central-occipital, temporal-occipital, and parietal-occipital). Legend: $F C=$ frontal-central, $F T=$ frontal-temporal, $\mathrm{CT}=$ central-temporal, $\mathrm{FP}=$ frontal-parietal, $\mathrm{CP}=$ central-parietal, $\mathrm{TP}=$ temporal-parietal, $\mathrm{FO}$ = frontal-occipital, $\mathrm{CO}=$ central-occipital, $\mathrm{TO}=$ temporal-occipital, $\mathrm{PO}=$ parietal-occipital. 
Table 1

\begin{tabular}{|c|c|c|c|c|}
\hline & Nold & ADMCI & PDMCI & Statistical analysis \\
\hline $\mathbf{N}$ & 75 & 75 & 75 & \\
\hline Age & $\begin{array}{c}70.1 \\
( \pm 0.8 \mathrm{SE})\end{array}$ & $\begin{array}{c}70.1 \\
( \pm 0.7 \mathrm{SE})\end{array}$ & $\begin{array}{c}71.2 \\
( \pm 0.8 \mathrm{SE})\end{array}$ & ANOVA: n.s. \\
\hline Gender (M/F) & $36 / 39$ & $34 / 41$ & $38 / 37$ & Kruskal-Wallis: n.s. \\
\hline Education & $\begin{array}{c}10.2 \\
( \pm 0.5 \mathrm{SE})\end{array}$ & $\begin{array}{c}10.9 \\
( \pm 0.5 \mathrm{SE})\end{array}$ & $\begin{array}{c}10.2 \\
( \pm 0.6 \mathrm{SE})\end{array}$ & ANOVA: n.s. \\
\hline MMSE & $\begin{array}{c}28.5 \\
( \pm 0.1 \mathrm{SE})\end{array}$ & $\begin{array}{c}25.1 \\
( \pm 0.3 \mathrm{SE})\end{array}$ & $\begin{array}{c}25.7 \\
( \pm 0.3 \mathrm{SE})\end{array}$ & $\begin{array}{c}\text { Kruskal-Wallis: } \\
\mathrm{H}=94.8, \mathrm{p}<0.00001 \\
\text { (Nold }>\mathrm{ADMCl}, \mathrm{PDMCl})\end{array}$ \\
\hline
\end{tabular}




\section{Interhemispheric lagged linear connectivity}

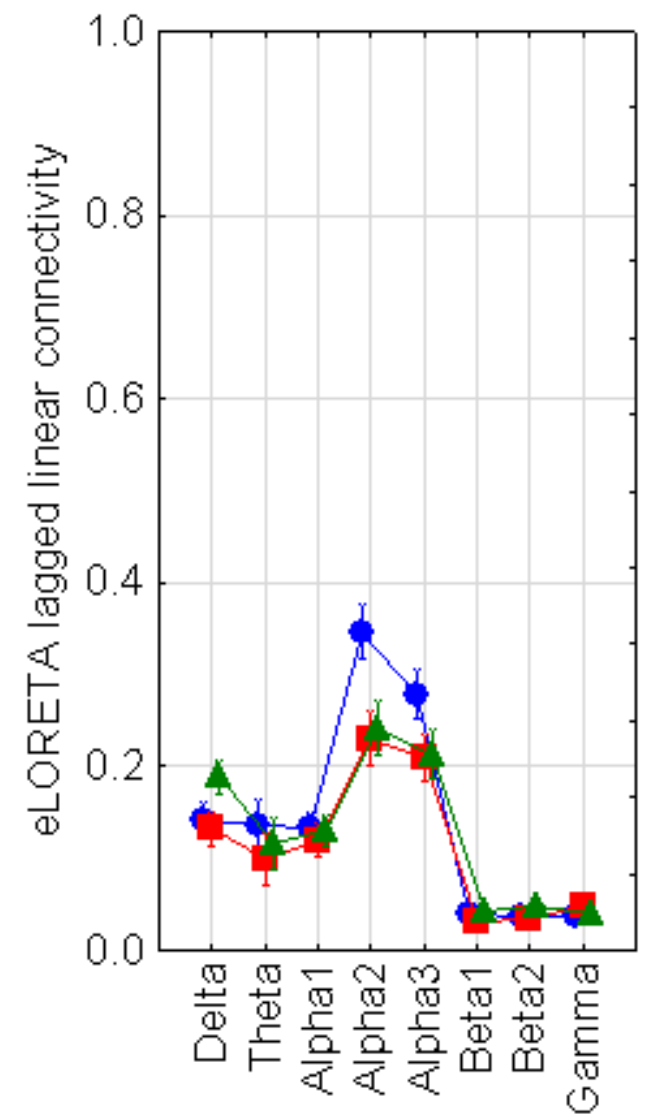

Frontal

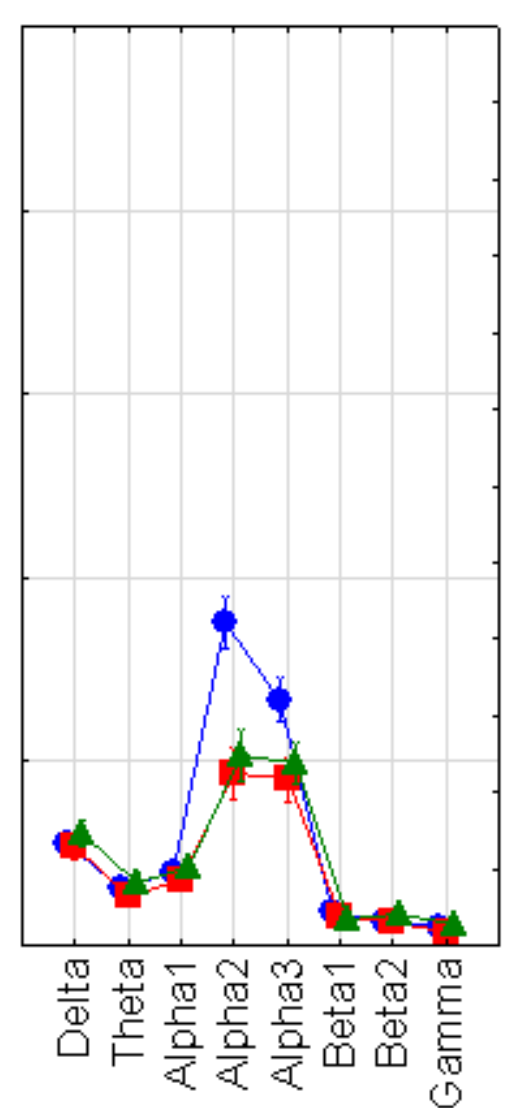

Central

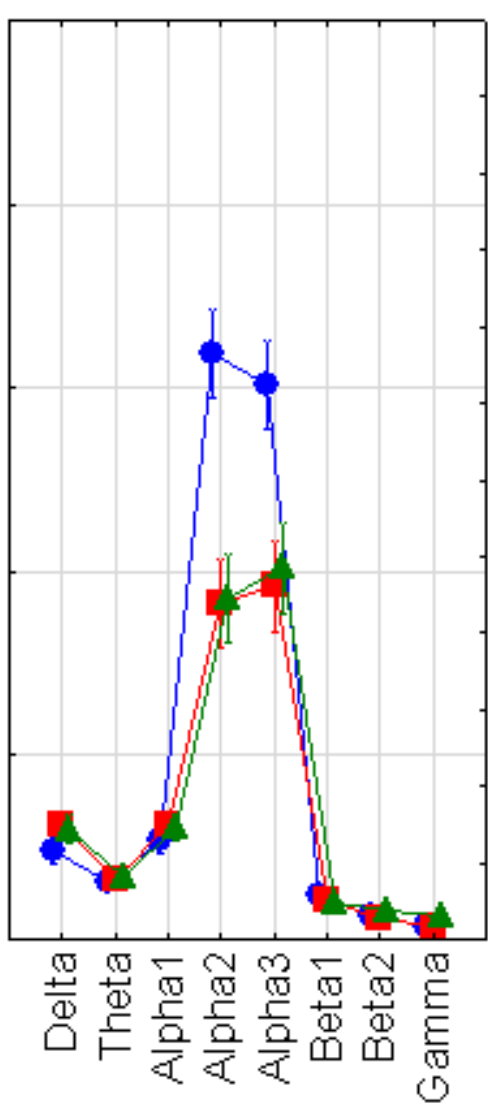

Parietal

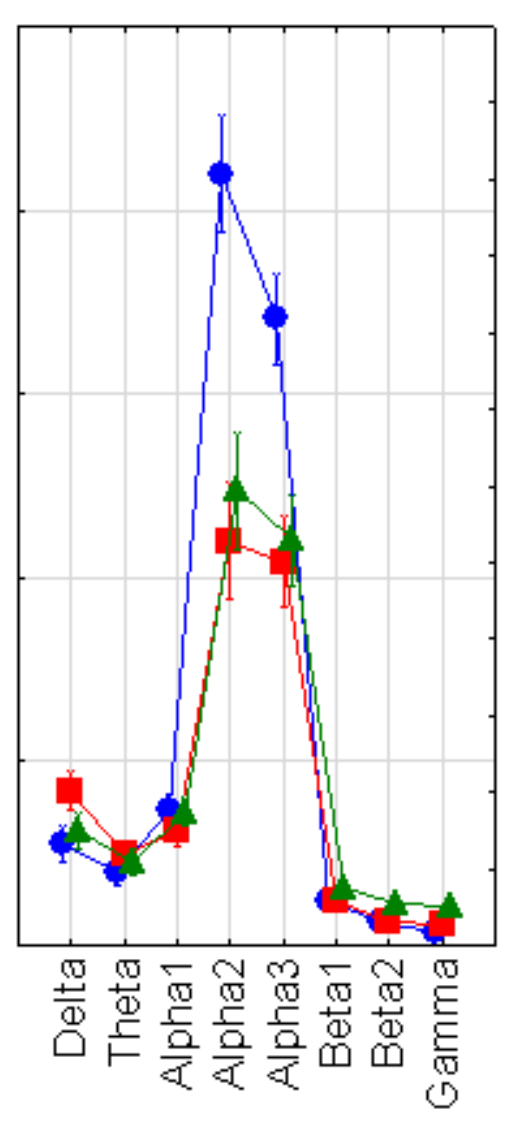

Occipital

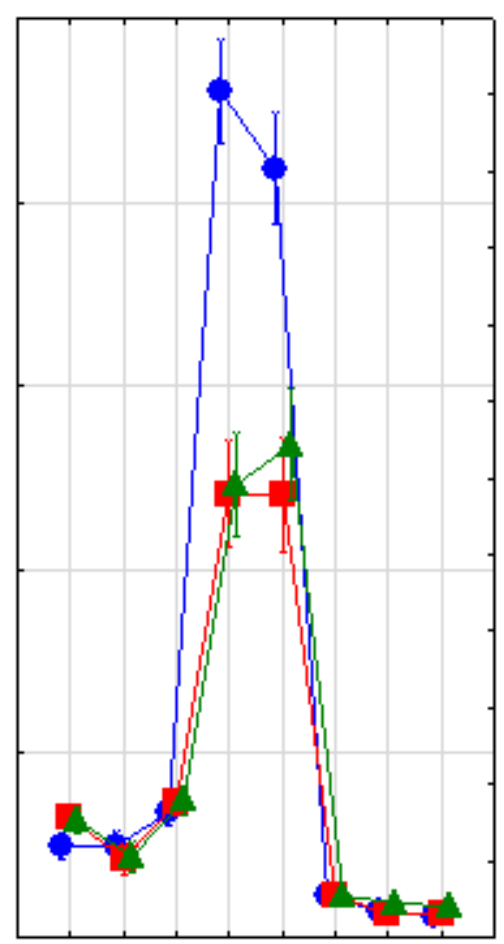

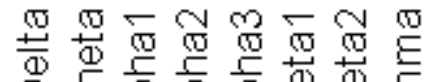

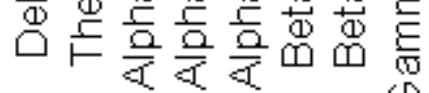
Temporal

Nold

Eᄑ $\mathrm{ADMCl} \quad \underline{\mathrm{E}} \mathrm{PDMCl}$ 


\section{Intrahemispheric lagged linear connectivity}

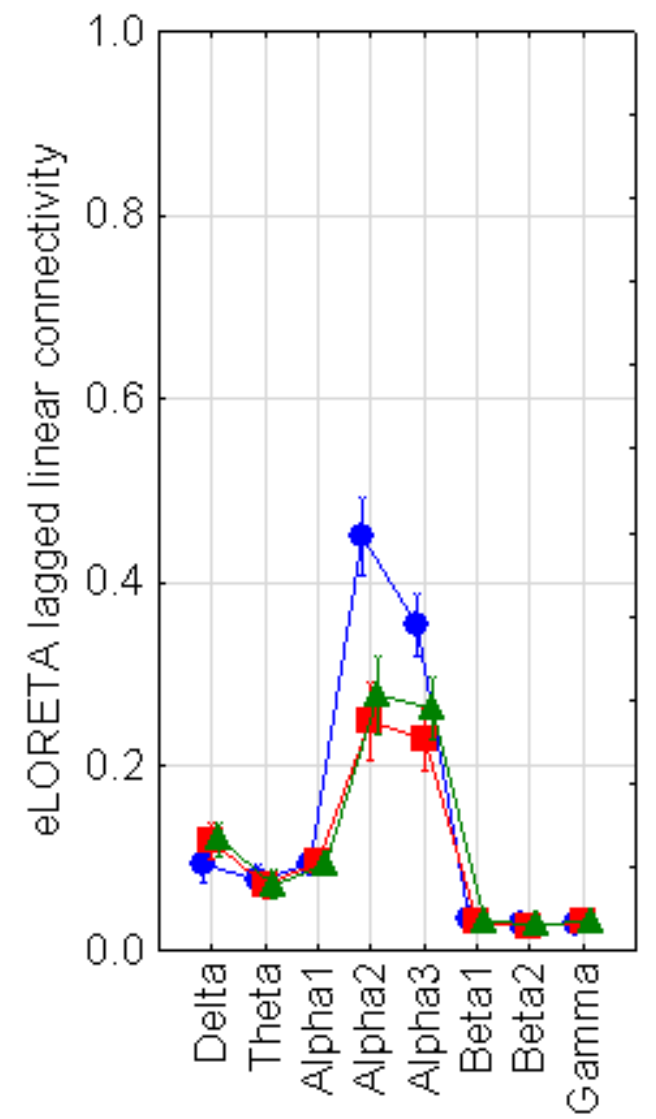

Frontal

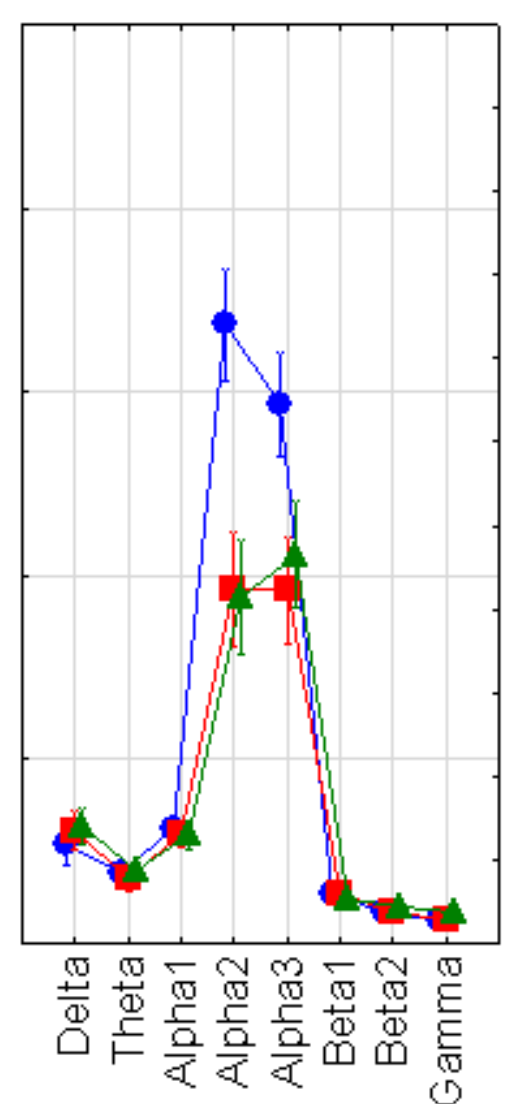

Central

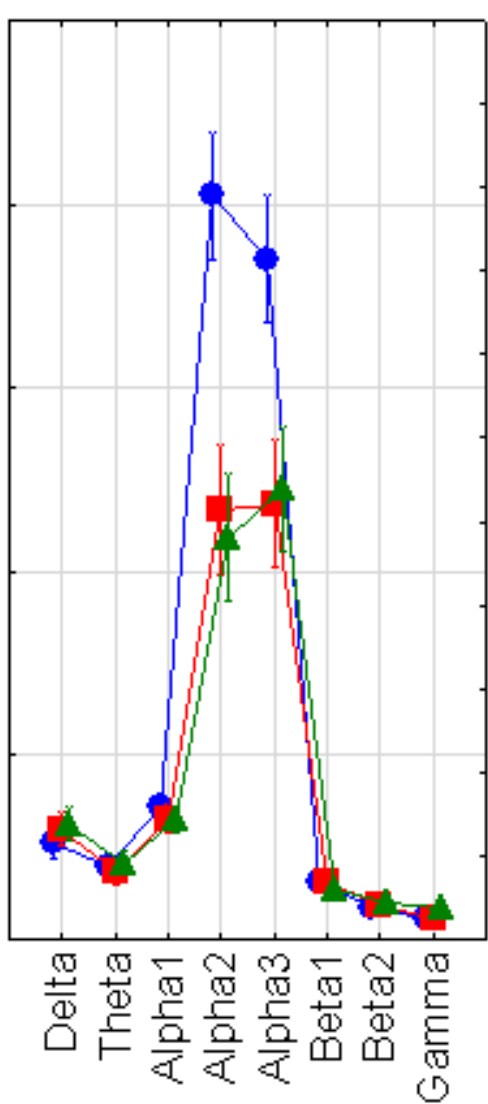

Parietal

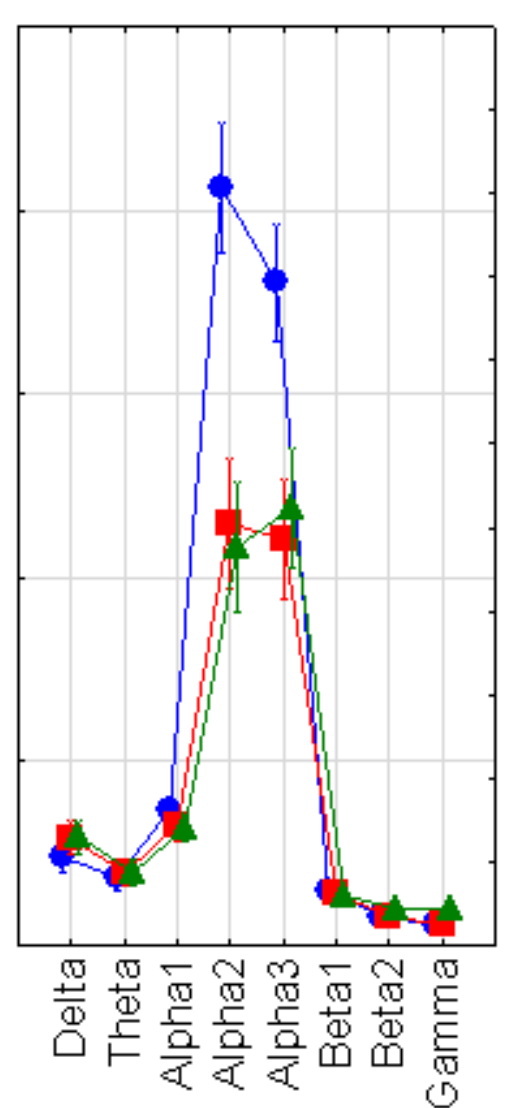

Occipital

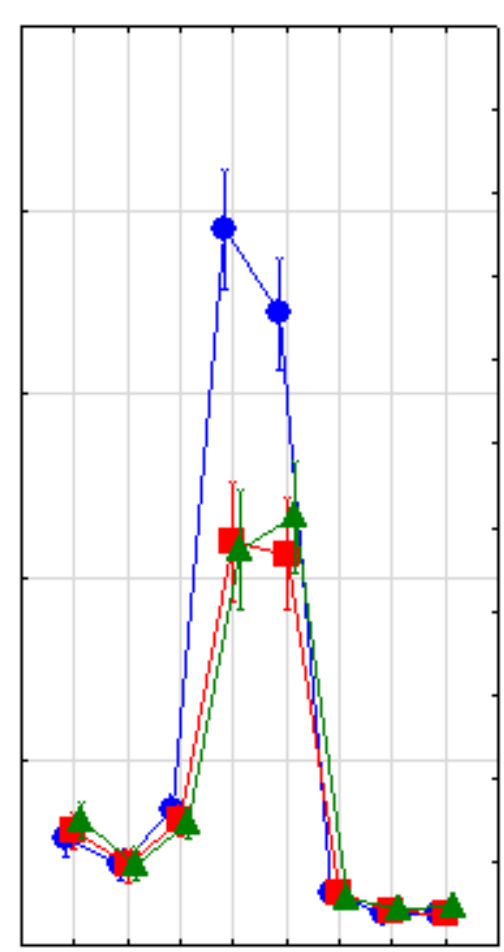

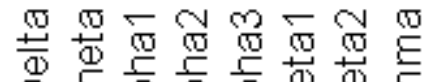

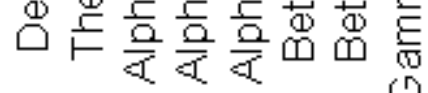
Temporal

Nold

Eᄑ $\mathrm{ADMCl}$ 프 PDMCl 


\section{Individual values of lagged linear connectivity}

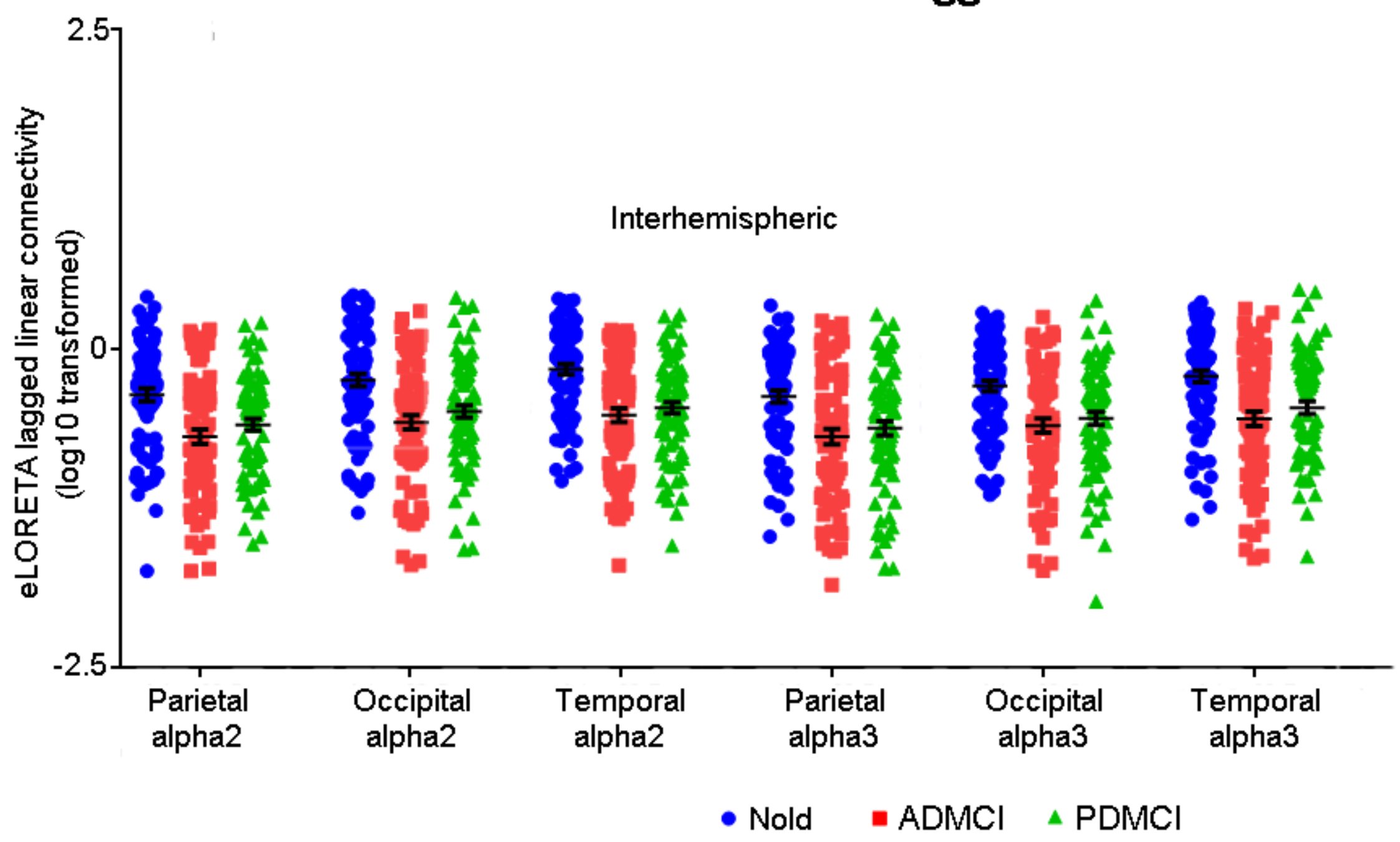

Intrahemispheric

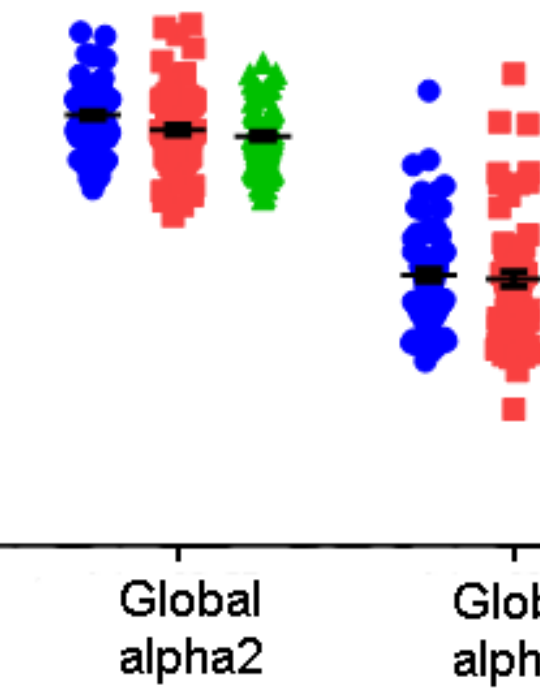


Scatterplot between lagged linear connectivity and MMSE score across Nold, ADMCI, and PDMCI
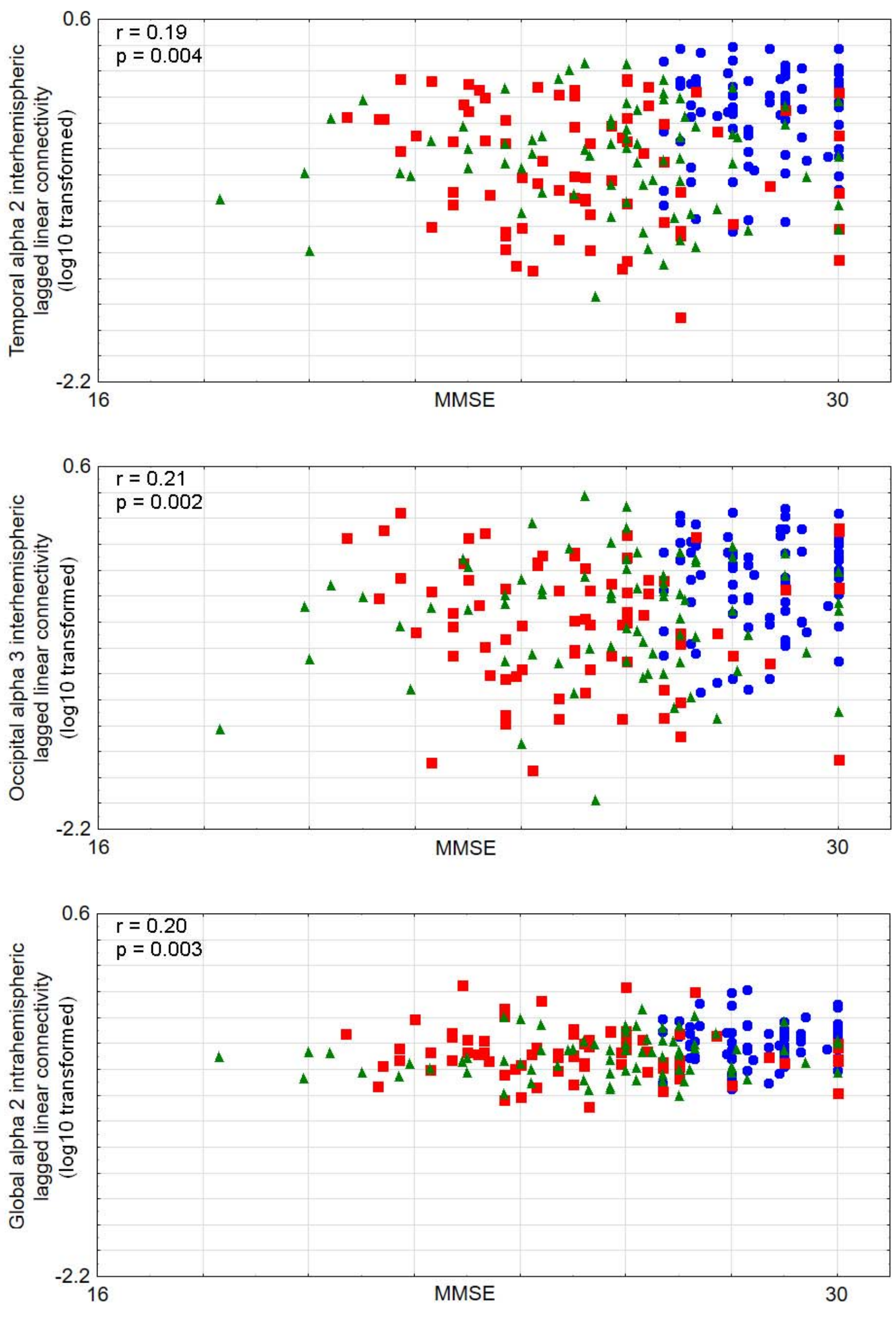

- Nold $\quad \mathrm{ADMCl} \quad \triangle \mathrm{PDMCl}$ 


\section{Classification among Nold, $A D M C I$, and PDMCI individuals based on eLORETA lagged linear connectivity of rsEEG rhythms}

Nold vs ADMCl

Temporal alpha 3 interhemispheric lagged linear connectivity

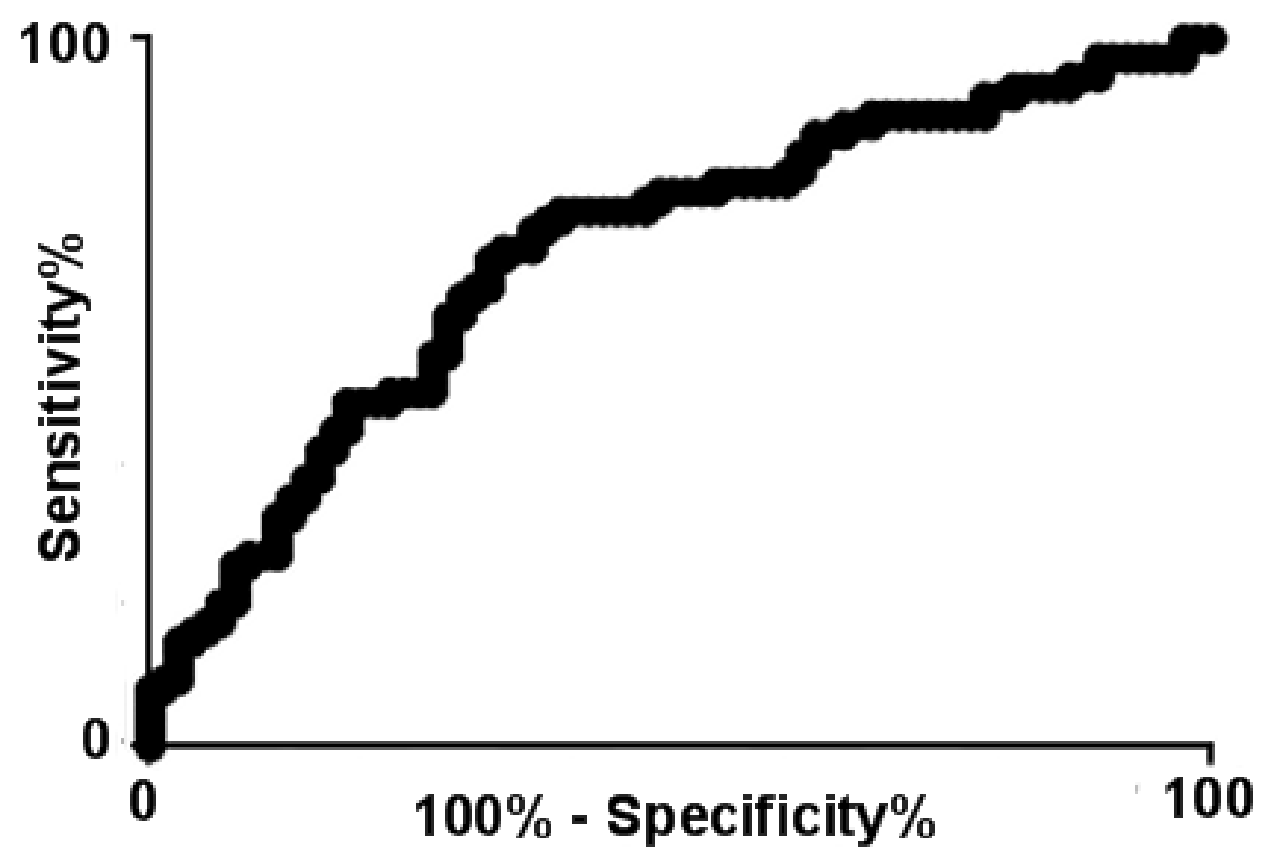

Nold vs PDMCl

Temporal alpha 2 interhemispheric lagged linear connectivity

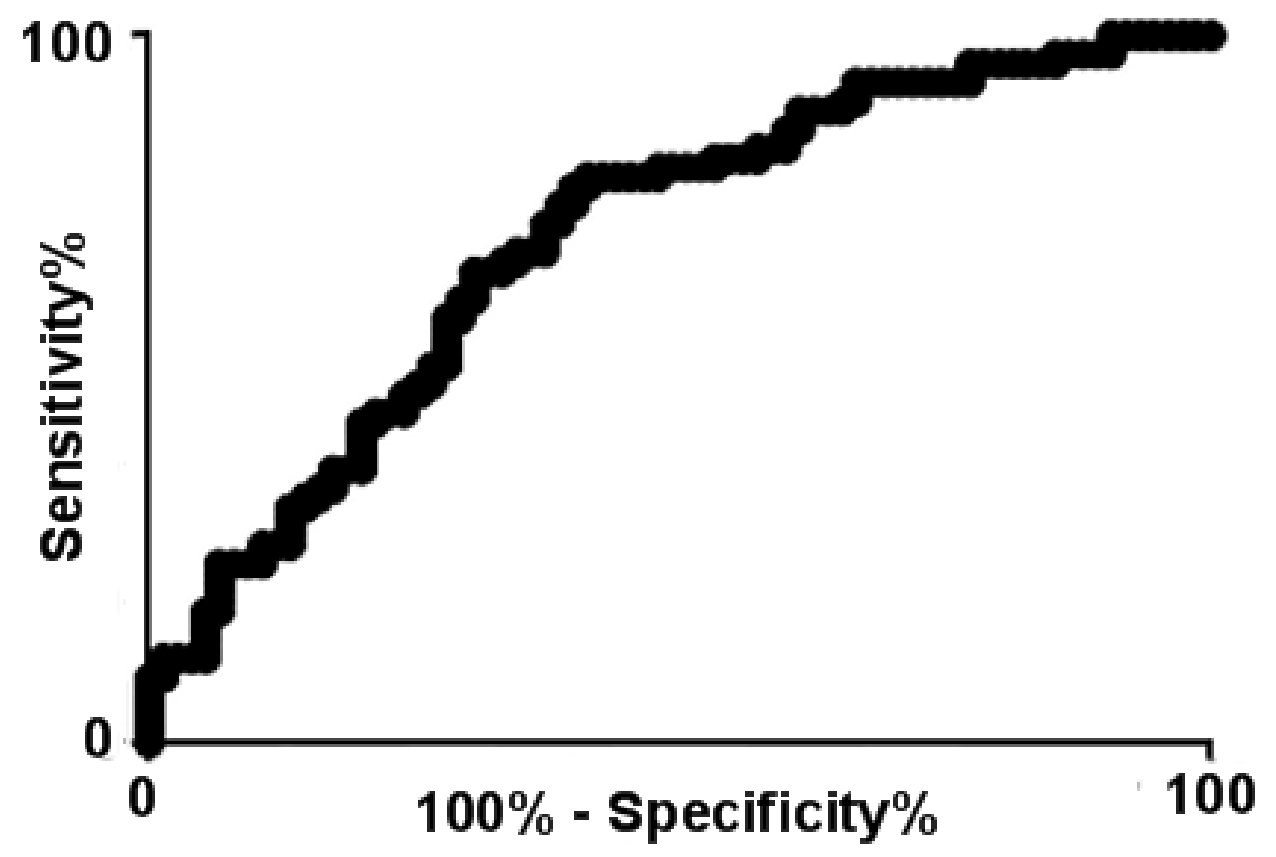


Alpha lagged linear connectivity
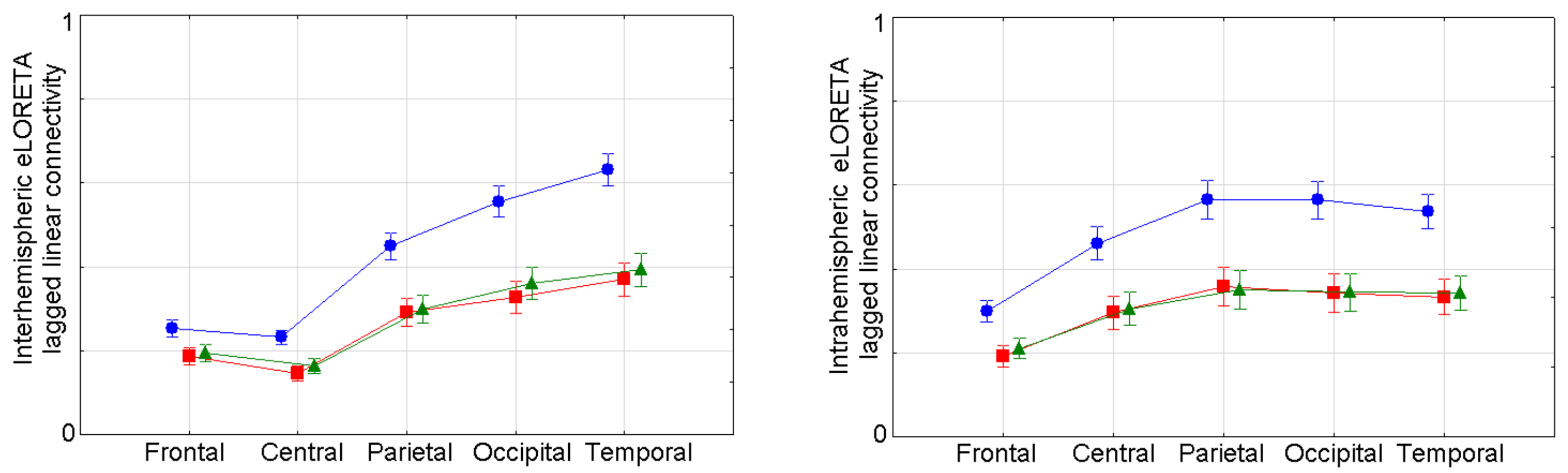

Nold

IE $\mathrm{ADMCl}$

포 $\mathrm{PDMCl}$ 


\section{Alpha intrahemispheric lagged linear connectivity}
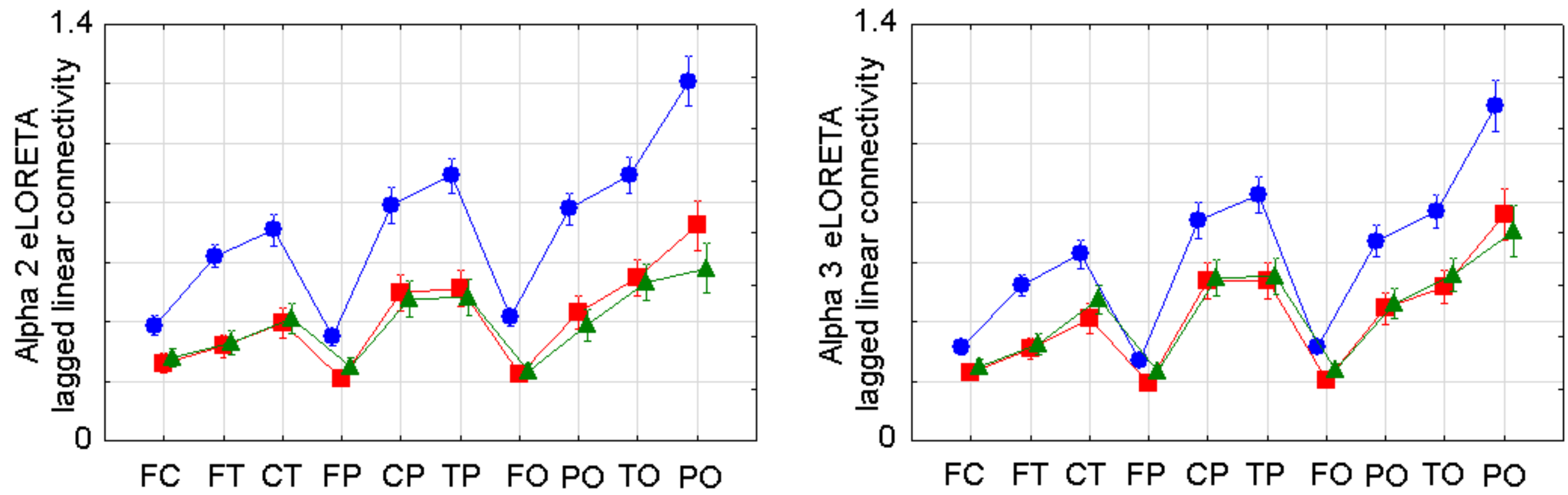

Nold

ADMCl $\mathrm{PDMCl}$ 